\title{
Churn flow in high viscosity oils and large diameter columns
}

2

\section{$6 \quad$ Abstract}

7 Churn flow is an important intermediate flow regime occurring in between slug and annular flow patterns

19 Keywords:

\author{
Shara K. Mohammed, Abbas Hasan, Georgios Dimitrakis, Barry J. Azzopardi \\ Faculty of Engineering, University of Nottingham, Nottingham NG7 2RD, United Kingdom
}

in two-phase flow, with profound implications in chemical and petroleum industry. The majority of studies

to date in churn flow have been carried out mainly using water or liquids of low viscosities and limited information exists regarding the behaviour of high viscosity liquids which resemble realistic process conditions. In this paper, a study that investigated churn flow and its characteristics in high viscosity oils (360 and 330 Pa.s) and large diameter columns (240 and 290mm) is presented for a first time. Transition to churn flow regime starts when the structure velocity, length and frequency of the liquid bridges, which appear at the end of slug flow, increase. In churn flow, gas flows at the core of the oil column with a wavy passage, leaving the top surface open to atmosphere with a possibility of creating a very long bubble. The average length of the bubbles seen to decrease with increasing the gas flow rate. While, no considerable change is observed in void fraction, structure velocity and film thickness at this flow pattern.

(2)

High viscosity liquids, transition to churn, churn flow, large diameter, Electrical Capacitance Tomography, volcanic conduits. 


\section{Introduction}

Churn flow, which is an intermediate flow regime that appears between slug and annular flow regimes, is an important flow pattern in gas-liquid two-phase flow. Churn flow occurs during operations in many hydrocarbons industries and chemical processes such as pipelines in oil and gas industry. It can also be found in some natural phenomena such as volcanos. The pressure drop, mass and heat transfer are design parameters which have a significant role in the safety and the stability of gas-liquid systems and can be affected during churn flow. In churn flow, the gas-liquid travels upward and downward in a churning or oscillating movement with a resultant of upward flow. This oscillating motion is a result of two forces, gravity and shear forces, acting in opposing directions on the falling film around Taylor bubbles. Churn flow was first defined by Zuber and Findlay (1965) as "churn-turbulent" bubbly flow. Then, it was considered as an intermediate region that occurs between slug and churn flow regimes by Hewitt and HallTaylor (1970). Finally, it was defined as churn flow regime by Taitel et al. (1980). Furthermore, Hewitt et al. (1985) reported similarities between these two flow regimes by employing a visual technique. In addition, a modified form of slug flow model was applied by De Cachard and Delhaye (1996) for churn flow. However, the pressure that drops in the pipe in churn flow is seen to be better predicted by annular flow model, Holt et al. (1999). Churn flow was correlated to be a developing form of slug flow regime. On the other hand, Barbosa Jr et al. (2001) defined this flow regime as it appears after the breakdown of slug flow when the velocity increases. Since churn flow is similar to annular flow regime in features, a number of studies considered it as annular flow. For instance, Nicklin (1962) used the name "semi-annular" flow to recognise the annular properties churn flow is distinguished from the annular flow regime based on 3 criteria. First, the change of the pressure gradient inside the pipe with an increasing gas flow rate. The friction and the intensive wave activity which result from the sudden breakdown of slug flow increase the pressure gradient significantly inside the pipe. Owen (1986) presented the change of the pressure gradient data against the dimensionless gas velocity for air-water flow in a $32 \mathrm{~mm}$ diameter vertical pipe. According to his results, the pressure gradient values showed a sudden drop at the transition to churn flow due to the high-frequency wave activity and friction. However, in Owen's work, the values of the pressure gradients decreased with an increasing gas flow rate at a constant liquid flow rate. The decrease in the amount of the interaction between the gas and the liquid is a reason of the decrease of the pressure gradient at the selected gas flow rate. Then by increasing the gas flow rate, the values of the pressure gradients increased again. 

accumulates and starts to flow upward in a form of large waves. This flow mechanism, which was proposed by Hewitt et al. (1985), is similar to the flooding phenomenon due to the flow of large waves. The third criterion, for starting churn flow, is the entrainment of the droplets from the large liquid fractions which travel as large flooding waves along the column. Wallis (1962) found that increasing the gas velocity decreases the entrained fraction to a minimum value (churn flow). Then a further increase in the upward gas flow rate increases the liquid entrained fraction in the annular flow. Churn flow in low viscosity liquids was also studied by Brauner and Barnea (1986), Sekoguchi and Mori (1997), Kaya et al. (2000), de Carvalho and Ferreira (2000), Furukawa and Fukano (2001), Sawai and Kaji (2001) and Azzopardi and Wren (2004). despite its importance. Such high viscosity liquids can be found for example in crude oil and bitumen production (with a viscosity up to $2000 \mathrm{~Pa} . \mathrm{s}$, Shu, 1984) and in polymer manufacturing (100-1000 Pa.s). It is also important to predict the volcanic degassing process where gas-Silicatic magmas rise in volcanic conduits as multiphase flow mixtures. The viscosity of the common type of magma is ranged from 100 to 1000 Pa.s. No experimental studies to date have so far introduced churn flow in liquids of 360 Pa.s viscosity. In addition, all existent empirical correlations in slug-churn flow transition are based on low viscosity liquids (commonly, water). Therefore, the characteristics of the dynamic of two phase flow using realistic liquids need more attention and investigation. The aim of this work is to investigate the characteristics of churn flow in very high viscosity liquids and large diameter columns for the first time. Two columns of 240 and $290 \mathrm{~mm}$ diameters and 360 and 330 Pa.s Silicone oil respectively were employed in this work. Electrical Capacitance Tomography (ECT) was used to collect information about the characteristics of the viscosity liquids and large diameter columns. Each rig consists of a large vertical column open to the 
330 Pa.s respectively. An Electrical Capacitance Tomography, ECT sensor is placed at $2.56 \mathrm{~m}$ from the gas inlet section in both columns in order to allow full development of the flow structure. The ECT sensor (with twin, 8 electrodes) is connected to a TFLR 5000 electronic box and a PC for data acquisition and processing. This non-intrusive sensor measures the cross-section distribution of capacitance in the column, which can be then correlated to the cross-section phase distribution for the non-conductive fluids. The sensor is capable of measuring up 5000 frames per seconds with excitation frequency range of $1-10 \mathrm{MHz}$.

Measured capacitances are converted into permittivity and concentration distribution as follows. The properties of the capacitance sensor are initially calculated or measured to generate a sensitivity matrix for the empty column. This matrix consists of a set of sub-matrices which elements are related to the individualpixels in a rectangular $32 \times 32$ grid that can be used to define the cross-section of the sensor/pipe. Normally, for a circular pipe, 812 pixels are used. An ECT sensor is calibrated using two different permittivity materials by first filling the sensor with low permittivity material and measuring all possible individual inter-electrode capacitances values. The same procedure is repeated for the sensor filled with high permittivity material. The calibration data obtained is then stored in a calibration-file which helps to set up the measurement-parameters for each measuring channel. Once the calibration has been completed, capacitances between all unique pairs of sensor-electrodes can be measured continuously. The possible unique capacitance values are $\mathrm{N}(\mathrm{N}-1) / 2$ per image frame or measurement, where $\mathrm{N}$ is the number of electrodes. Therefore 28 unique capacitance values per plane were obtained for the experimental work described in this paper. The measured capacitances were then normalised to the measured values during the calibration of the system. The overall volume ratio (VR), which is simply the ratio of the two materials (phases) presented in the pipe can then be easily obtained. For more details on ECT, see for example, Byars (2001) and Abdulkareem (2011).

Azzopardi et al. (2010) validated the ECT using the Wire Mesh Sensor (WMS) for air/Silicone oil flow in a vertical pipe at different flow regimes (i.e. bubbly, slug and churn flow). Although WMS is an intrusive technique, placing a WMS sensor downstream the ECT (to prevent flow disturbances across the ECT) allows the ECT to be validated. Figure 1 shows the comparison of the overall cross-sectional averaged void fraction between ECT and WMS. The standard deviation between two measurement techniques is displayed in Fig. 2. 


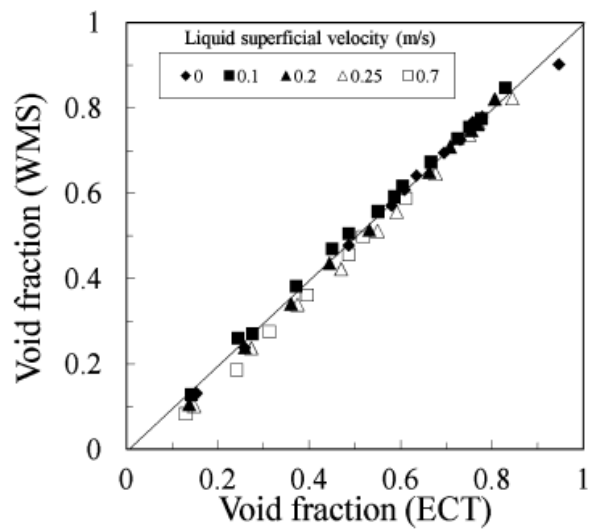

Figure 1: Averaged void fraction measured using ECT and WMS

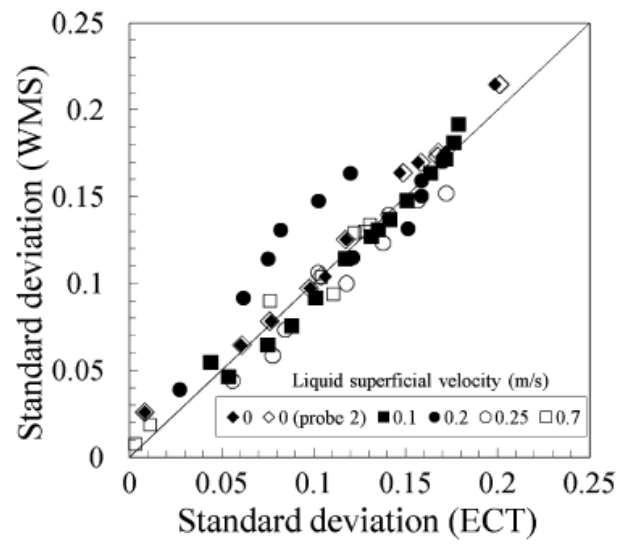

Figure 2: Standard deviation of measurements between ECT and WMS, Azzopardi et al. (2010).

In addition, ECT technique was compared and validated using other measurement techniques as well as CFD simulations. Chaminda Pradeep et.al (2014), investigated the validation of an ECT using gammaray meter. They reported that ECT showed most of the features and characteristics seen in the gamma-ray meter. CFD simulations were also conducted and the results were in good agreement with their experimental work. Marashdeh (2009) carried out a series of experiments to validate (quantitatively and qualitatively) an ECT using Magnetic Resonance Imaging and fibre optics probes in two phase fluidized bed. He showed that the shape of the bubbles obtained and the voidage distribution from MRI and ECT are almost the same. He reported that, the time averaged cross sectional of solids concentrations calculated from the fibre optic probes and ECT exhibited very good agreement.

Figure 3 displays the experimental setup which is used in the present work showing the gas injection arrangements, instrumentation, and the dimensions. The rig is also incorporated a temperature measurement sensor (thermocouple) to indicate the temperature of the air at the gas lines besides the air-oil mixture in 
the column. Both columns contain stagnant Silicone oil with initial heights of $3.30 \mathrm{~m}$, the properties of the fluids are listed in Table 1. The gas injection system consists of two main gas lines to obtain a wide range of gas flow rates, high pressure of $6 \mathrm{bar}$ and low pressure of $2 \mathrm{bar}$. The high-pressure line is connected to 5 flow meters and pressure gauges. Then each line is divided into 5 more lines. Thus, the total number of the gas injection lines is 25 lines distributed equally at the bottom of the column. Sealed pressure transmitters were mounted along the $290 \mathrm{~mm}$ diameter column to indicate a continuous pressure outputs. The 2 Keller, PR-25/8797.1-5 transmitters are installed at 2.2 and $3.6 \mathrm{~m}$ from the gas inlet section. The pressure measurements were collected at a sampling rate of $50 \mathrm{~Hz}$ for $300 \mathrm{~s}$ at flow rate range of $10-3000 \mathrm{~L} / \mathrm{min}$.

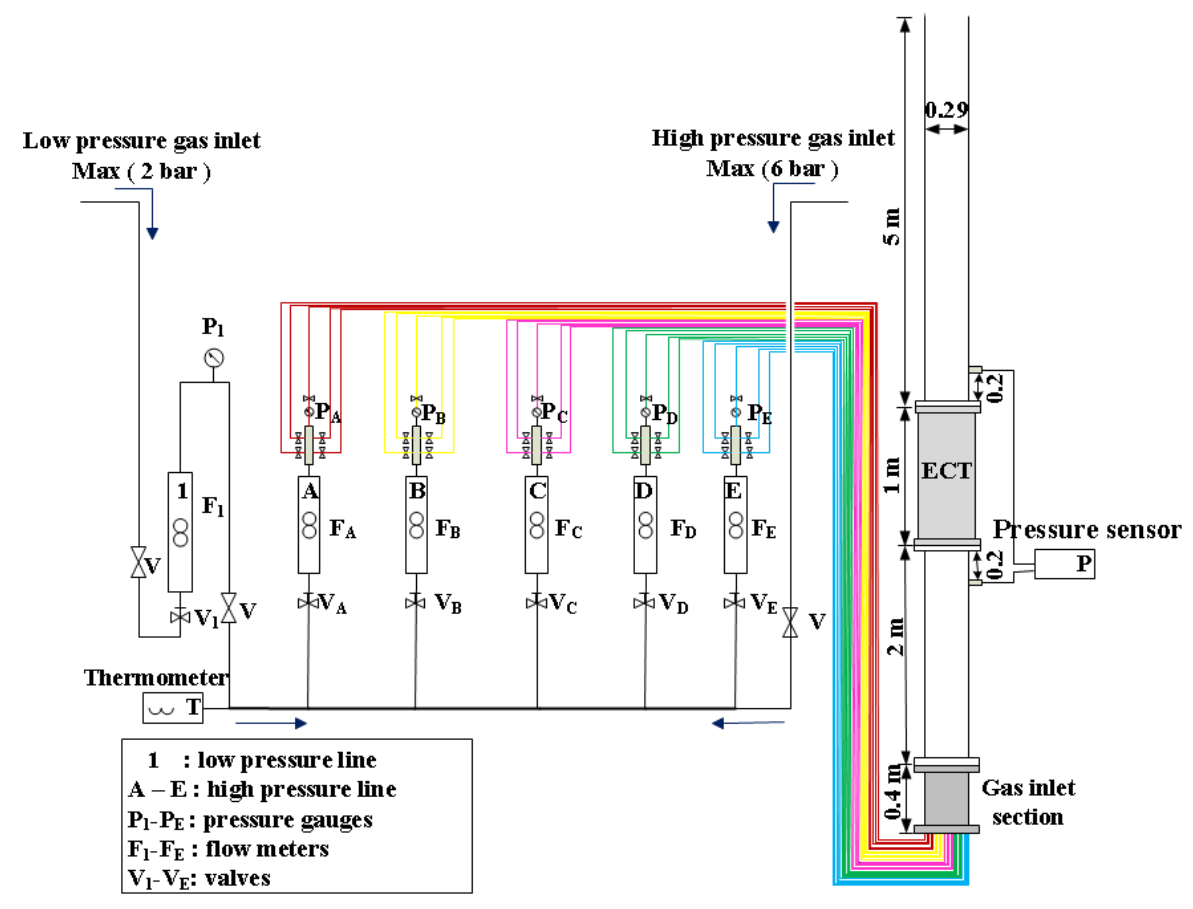

Figure 3: The experimental setup employed to study the flow structure of gas-high viscosity liquids.

Through the gas inlets, air of superficial velocities $0.127-0.314$ and $0.108-0.566 \mathrm{~m} / \mathrm{s}$ was injected into the 240 and $290 \mathrm{~mm}$ diameter columns respectively. Data acquisition time for each run was $600 \mathrm{~s}$ with a sampling rate of $50 \mathrm{~Hz}$. 


\begin{tabular}{|c|c|c|c|c|}
\hline Fluid (1) & \multicolumn{4}{|c|}{ Silicone oil } \\
\hline $\begin{array}{l}\text { Column diameter } \\
\text { (m) }\end{array}$ & $\begin{array}{l}\text { Viscosity } \\
\text { (Pa.s) }\end{array}$ & $\begin{array}{l}\text { Density } \\
\left(\mathrm{Kg} / \mathrm{m}^{3}\right)\end{array}$ & $\begin{array}{l}\text { Surface tension } \\
(\mathrm{N} / \mathrm{m})\end{array}$ & $\begin{array}{l}\text { Eötvös number } \\
\qquad \mathrm{G}_{\mathrm{l}} \mathrm{D}^{2} / \delta\end{array}$ \\
\hline 0.24 & 360 & 950 & 0.02 & 26812 \\
\hline 0.29 & 330 & 950 & 0.02 & 39148 \\
\hline Fluid (2) & \multicolumn{4}{|c|}{ Air } \\
\hline $\begin{array}{l}\text { Column diameter } \\
\text { (m) }\end{array}$ & $\begin{array}{c}\text { Gas injections diameters } \\
\qquad(\mathrm{mm})\end{array}$ & $\begin{array}{l}\text { Density } \\
\left(\mathrm{Kg} / \mathrm{m}^{3}\right)\end{array}$ & $\begin{array}{c}\text { Gas-line pressure } \\
\text { bar }\end{array}$ & $\begin{array}{c}\text { Temperature } \\
\left({ }^{\circ} \mathrm{C}\right)\end{array}$ \\
\hline 0.24 & 3 & 1.225 & 6 & $20-23$ \\
\hline 0.29 & 4 & 1.225 & 6 & $19-22.5$ \\
\hline
\end{tabular}

The overall average void fraction, $\varepsilon g$ was also calculated from the level swell (i.e. by monitoring the oscillation level at the top section of the column and determining the initial height of the liquid, $H_{\text {liquid }}$ before gas injection and the height of the gas-liquid mixture, $H_{m i x}$ after gas injection). This can be calculated based on the assumption that the volume of the liquid in the column remains constant (Hills, 1976, Al-Oufi et al., 2010). Therefore; $\varepsilon g=\left\{\left(H_{m i x}-H_{\text {liquid }}\right) / \mathrm{H}_{m i x}\right\}$. Table 2 shows the relative error between measured (from ECT) and calculated void fraction. It should be mentioned that, as the gas superficial velocity increases, determination of $H_{\text {liquid }}$ becomes more difficult as the liquid becomes milky and the considerable sheared bubbles stick into the wall of the Perspex pipe which affect the visual appearance of the silicone oil level.

Table 2: Comparison of measured and calculated void fraction for $240 \mathrm{~mm}$ diameter column

\begin{tabular}{|c|l|l|l|l|}
\hline \multirow{3}{*}{ Flow regime } & \multirow{2}{*}{ Gas superficial velocity $(\mathrm{m} / \mathrm{s})$} & \multicolumn{3}{|c|}{ Void fraction } \\
\cline { 3 - 5 } & & Level swell & ECT & Relative error \\
\hline \multirow{5}{*}{ Slug flow } & 0.016 & 0.198 & 0.373 & 0.468 \\
\cline { 2 - 5 } & 0.028 & 0.321 & 0.432 & 0.258 \\
\cline { 2 - 5 } & 0.114 & 0.491 & 0.487 & -0.008 \\
\hline \multirow{5}{*}{ Transition to churn flow } & 0.127 & 0.506 & 0.496 & -0.020 \\
\cline { 2 - 6 } & 0.148 & 0.509 & 0.491 & -0.036 \\
\cline { 2 - 6 } & 0.175 & 0.519 & 0.507 & -0.024 \\
\cline { 2 - 6 } & 0.201 & 0.528 & 0.501 & -0.053 \\
\cline { 2 - 6 } & 0.232 & 0.546 & 0.505 & -0.081 \\
\cline { 2 - 6 } & 0.260 & 0.565 & 0.451 & -0.252 \\
\cline { 2 - 6 } & 0.284 & 0.587 & 0.435 & -0.348 \\
\cline { 2 - 6 } & 0.314 & 0.605 & 0.505 & -0.196 \\
\hline
\end{tabular}




\subsection{Visual observation and time series of void fraction}

Videos and photos were obtained and compared with the data of the time series of void fraction. Images were also reconstructed from the recorded data using Tikhonov iterated regularization technique. Transition to churn flow was observed at gas superficial velocities of $0.127-0.314$ and $0.108-0.243 \mathrm{~m} / \mathrm{s}$ in the 240 and $290 \mathrm{~mm}$ diameter columns respectively. Churn flow appeared at $0.276-0.566 \mathrm{~m} / \mathrm{s}$ in the larger diameter column.

At a gas superficial velocity of $0.108 \mathrm{~m} / \mathrm{s}$, regions of high frequency activity started to appear. This extends systematically as the gas flow rate is further increased. These regions are shown as (B) on the time series of void fraction in the figures below and also depicted on the photos of the column. Figure 4 displays the time series of void fraction and the equivalent photos which show the flow structure at the selected gas flow rates. The transition to churn flow regime starts when the length and the frequency of the regions of the high frequency activity, which appeared at the end of slug flow, increases. These regions of high frequency activities were observed as the liquid bridges flow up and down. The void fraction of these regions is lower than that in Taylor bubbles. The source of liquid bridging is believed to be from the drained falling film from the Taylor bubbles. With increasing gas flow rate, the length of Taylor (A) bubbles increases until it reaches the total height of the column, producing larger volumes of falling film which lead to increase the length of the high frequency liquid bridges region and their frequency decreases. The high frequency liquid bridges region is considered to be churn flow. The maximum amount of the coalescence between Taylor bubbles occurs in this flow regime (transition to churn). The length of Taylor bubbles increases dramatically with increasing gas input till it reaches the total height of the column.

According to the visual observations, Taylor bubbles become deformed when the gas flow rate is increased. This is due to increasing the rate of the coalescence and therefore increasing the length of the bubbles. The Top and/or the bottom of the bubbles lose the round shape. The liquid slugs between the bubbles eventually disappear and get replaced by the churn areas (B). The churn areas are connected to the deformed Taylor bubble by a small neck (See (A) in Figure 4). The deformed long Taylor bubbles are referred to as long bubbles at this flow regime. Coalescence between bubbles appears from about 100-150s and $230-280 \mathrm{~s}$ for $0.243 \mathrm{~m} / \mathrm{s}$ gas superficial velocity in the time series data. The photos of the column in 
(B) show the developing of the churn areas which become more complicated and deformed with increasing gas flowrate. By the end of this flow regime, only a small number of long bubbles appear.

The Silicone oil which used in this work showed the behaviour of Newtonian liquids during the viscosity bench test. The viscosity of the oils was measured by applying a certain shear rates using a rotating spindle. The viscosity of the oil was found to change with changing temperature, not with the amounts of applied shear force, (Papanastasiou et al., 1999).
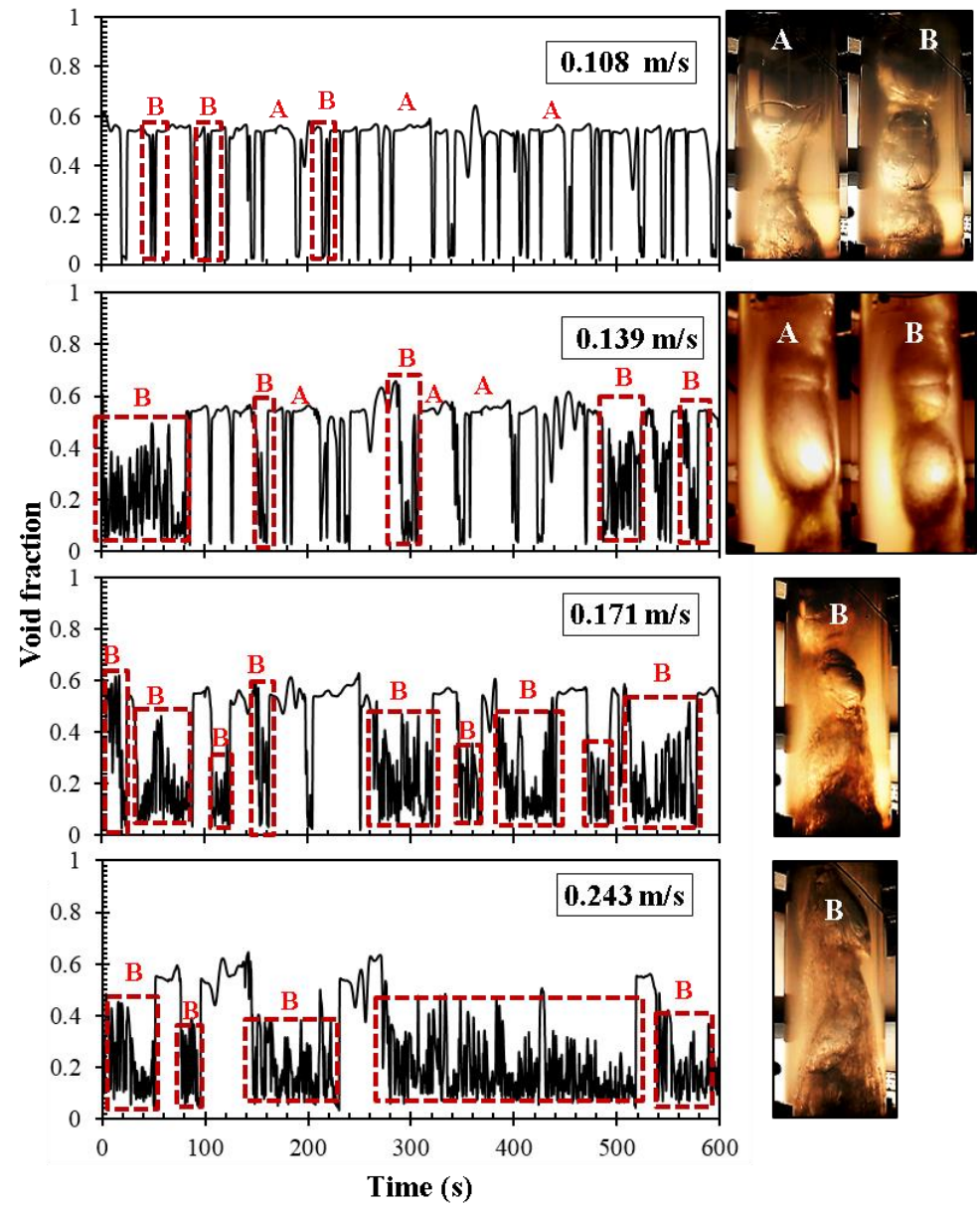

Figure 4: Time series of void fraction and photos of transition to churn flow in 330 Pa.s Silicone oil and $290 \mathrm{~mm}$ diameter column at different gas superficial velocities. A is the large bubbles, $\mathrm{B}$ is the churn areas in both photos and the time series

The time series data from the ECT besides the videos obtained from the top section at different positions of the column provide local information about the flow behaviour in the column. Therefore, an overall picture of the gas-high viscosity liquid behaviour in the column is presented in a schematic drawing in Figure 5. This schematic drawing shows the overall flow structure in the column at the transition to churn 

constant gas superficial velocity $(0.205 \mathrm{~m} / \mathrm{s}$.).

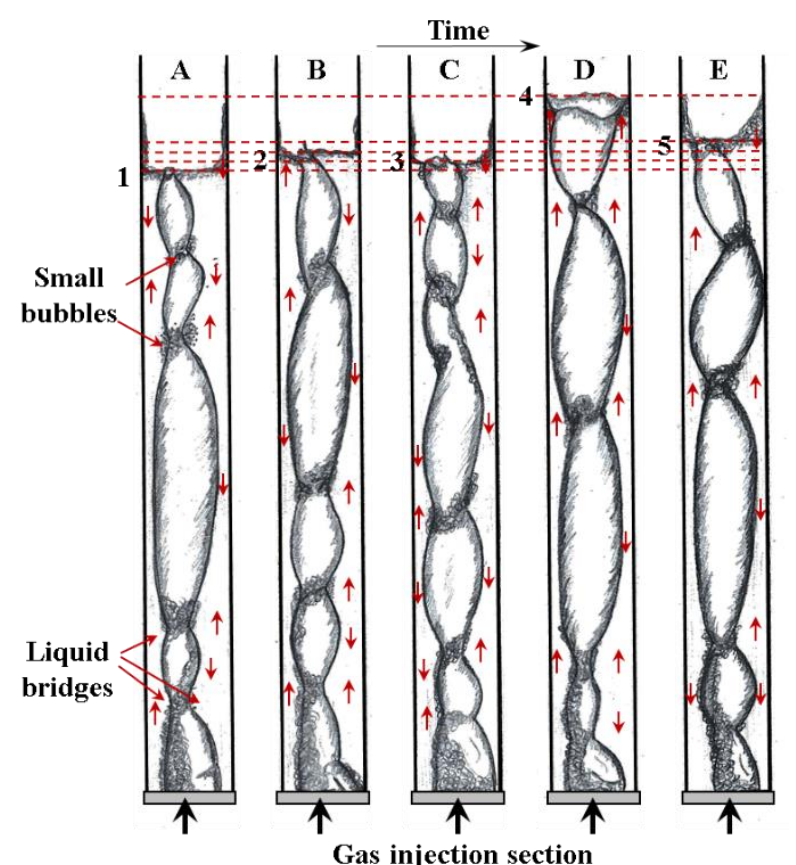

Figure 5: Schematic drawing showing the transition to churn flow pattern in high viscosity liquids and large diameter columns. The arrows in the figure correspond to the direction of the liquid flow, the numbers at the top section of the column corresponding to the liquid levels in the column. The gas superficial velocity is $0.205 \mathrm{~m} / \mathrm{s}$.

At a gas superficial velocity of $0.276 \mathrm{~m} / \mathrm{s}$, the flow structure changed significantly. The long bubbles disappeared and the churn areas dominated the flow structure. According to the time series data and the photos shown in Figure 6, and the schematic drawing in Figure 7, churn flow consists of two regions. First an open gas core with a thick liquid film with the possibility of liquid bridging the cross-section creating series of short bubbles (columns D and E in Figure 7 and the photos in Figure 6). This gas core might not exist at the centre of the column. Subsequently, with increasing gas flow rate, the gas builds up and push the liquid (column A in Figure 7) creating a very long bubble with a falling thin film. This long bubble bursts at the top section of the column and remain open to the atmosphere. This open large core is shown in Figure 6 at $120-180 \mathrm{~s}$ (A) in $0.566 \mathrm{~m} / \mathrm{s}$ gas superficial velocity and (B) in Figure 7 . Then the falling film, which drains along the pipe wall, accumulates at the bottom of the column (column $\mathrm{C}$ in Figure 7 ) and creates the next churn unit. The schematic drawing in Figure 7 shows the overall behaviour churn flow regime along the column, as it described earlier, at a constant gas flow rate and at different times. 


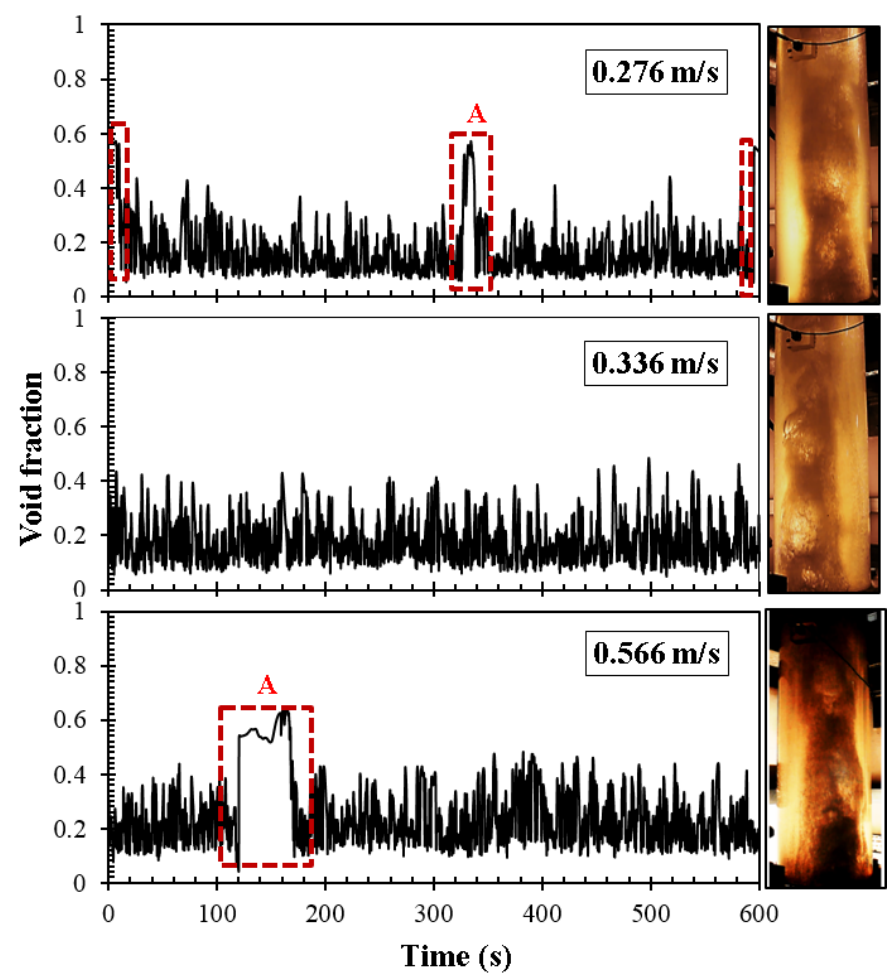

Figure 6: Time series of void fraction and photos showing churn flow in 330 Pa.s Silicone oil and 290 mm diameter column. The marked areas correspond to the large bubble and the photos show the churn regions.

Churn flow can also be distinguished from the transition to churn flow regime by the sound of the gas flowing inside the column. At the end of slug flow and the transition to churn flow regime the sound of the bubble eruption at the top surface could be heard with every single bubble and is totally different from the, the sound generated by the flowing fluids in the churn flow regime. The open gas core sounds like the volcanic conduit during volcanic activity. This continuous sound of the air passage through the viscous oil stops when the fraction of the drained liquid increases at the bottom of the column. At this stage, the gas builds up and pushes the drained liquid until the liquid fraction becomes very thin and bursts at the top section. Then the sound from the open core starts again. The sounds of the air passing through the high viscosity liquid which used in this work were approximately similar to the Arenal Volcano in Costa Rica. The volcano sounds are studied by Woulff and McGetchin (1958), Richards (1963), Garcés and McNutt (1997), and Dubosclard et al. (2004). 


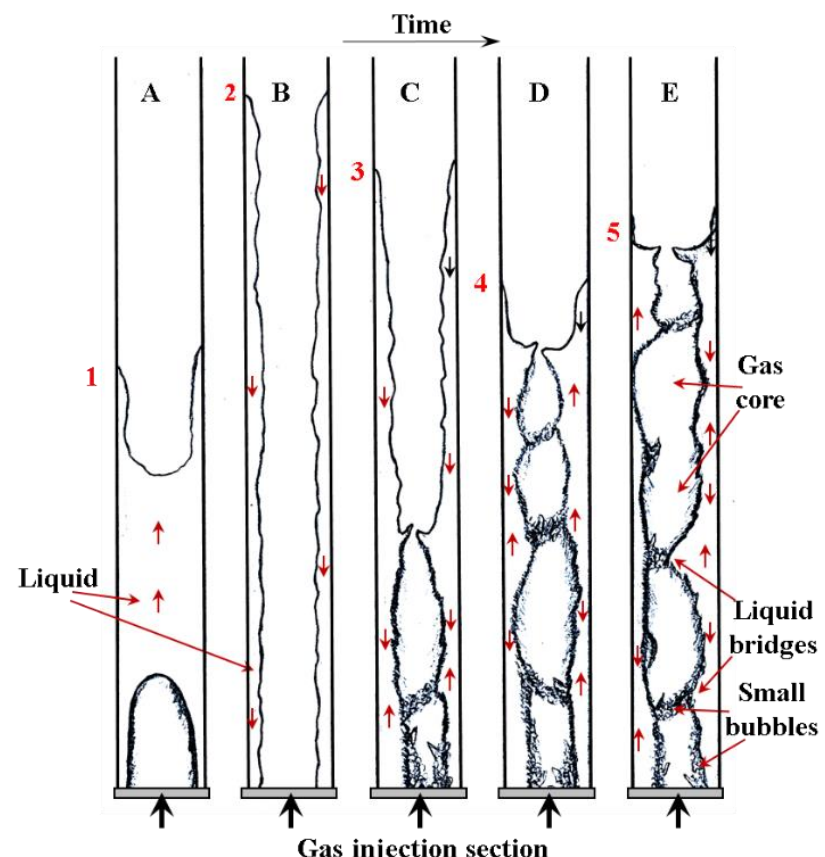

Figure 7: Schematic drawing showing churn flow pattern in high viscosity liquids and large diameter columns. The arrows in the figure correspond to the direction of the liquid flow, the numbers at the top section of the column corresponding to the liquid levels in the column. D and E are the more common structure for this flow regime. A-C occur when the liquid accumulates at the bottom of the column and the gas build up and rise as one long bubble and carry the whole liquid up to drain again as a falling film. The gas superficial velocity is $0.566 \mathrm{~m} / \mathrm{s}$.

The percentage of churn is calculated from the time of churn and the overall flow of each gas flow rate. The time of churn can be defined as the time when the areas of the high frequency activity (churn areas) pass through the ECT planes. Figure 8 displays the effect of gas flow rate on the time of churn in high viscosity liquids and large diameter pipes. It should be noted that data in Fig. 8 was read and extracted qualitatively from void fraction data measured from the ECT whose uncertainty was already reported in Fig. 9. In the $290 \mathrm{~mm}$ diameter column, the time of churn increased significantly with increasing the gas flow rate at the transition to churn regime (from 0 to $80 \%$ ). While it decreased slightly from $96 \%$ to $91 \%$ in churn flow regime. This slight decrease in time of churn can be attributed to the single long bubbles that appear at the end of this flow regime. The time of churn increased by approximately $22 \%$ over the range of gas superficial velocities at which ECT measurements were taken $(0.127-0.314 \mathrm{~m} / \mathrm{s})$. According to data obtained using the pressure transducers for a wider range of gas flow rates, it continued increasing to about $79 \%$. 


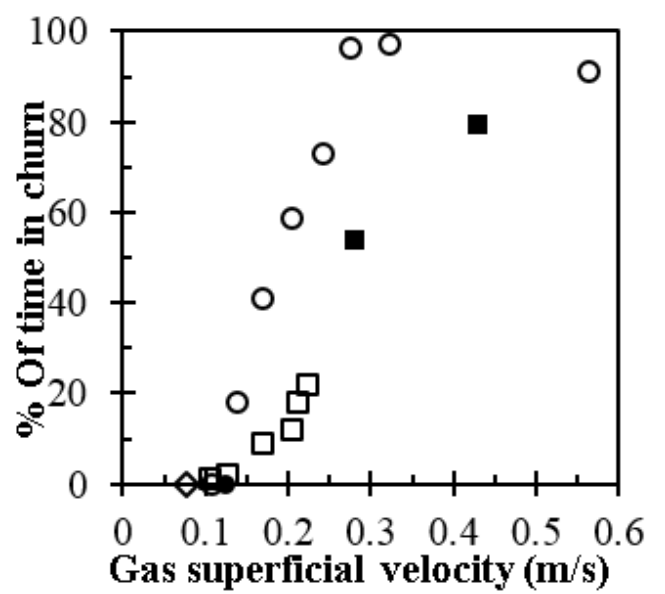

Figure 8: Time of churn calculated from the time series of void fraction of 240 and $290 \mathrm{~mm}$ diameter columns using the ECT, the pressure transducers in the smaller diameter column and the transition points are calculated from two straight lines on drift flux $\left(\mathrm{U}_{\mathrm{gs}} / \alpha_{\mathrm{g}}\right.$ vs $\left.\mathrm{U}_{\mathrm{gs}}\right)$. $\square 240 \mathrm{~mm} \mathrm{ECT,} 240 \mathrm{~mm}$ pressure transmitters, $\diamond 240 \mathrm{~mm}$ transition point, $\circ 290 \mathrm{~mm} \mathrm{ECT,} \mathrm{\bullet} 290 \mathrm{~mm}$ transition point.

Figure 9 compares the average void fraction in two different flow regimes and two different column diameters. In general, mean void fraction decreases with increasing gas flow rate in both columns. In the $290 \mathrm{~mm}$ diameter column, the mean void fraction continues to decrease in the transition to churn flow until it stabilises when churn flow is achieved. It decreases from 0.455 to 0.284 when gas superficial velocity was varied from, 0.108 to $0.243 \mathrm{~m} / \mathrm{s}$. This is due to the rise in the time of churn with increasing gas flow, as void fraction is lower at the churn sections. Then it varies between 0.259 to 0.250 from $0.276 \mathrm{~m} / \mathrm{s}$ and higher gas superficial velocities (churn flow).

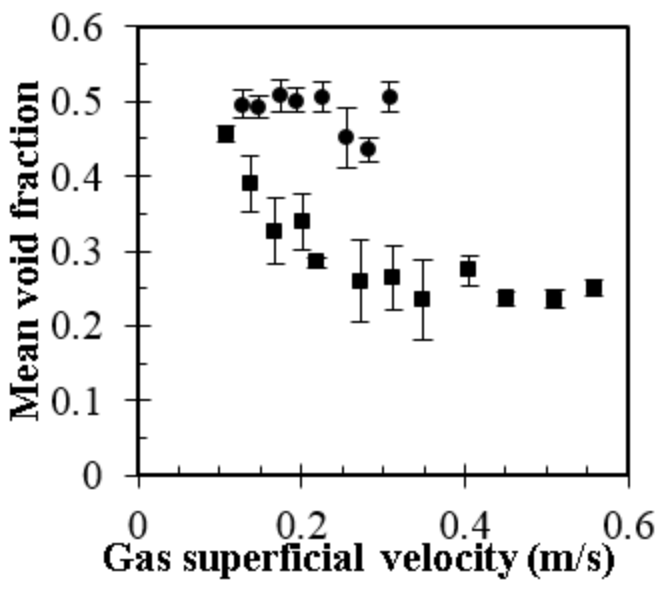

Figure 9: The effect of gas superficial velocity on the mean void fraction in high viscosity liquids and large diameter columns. $\bullet \mathrm{D}=240 \mathrm{~mm}, \boldsymbol{\nabla}=290 \mathrm{~mm}$.

In this flow regime, the structure is dominated by the low void fraction churn, and this explains the stability of void fraction values. Therefore, increasing gas flow rate at this flow regime does not limit the 
volume fraction of the gas which can pass through the viscous liquid column. This behaviour could be important for the volcanic degassing process. In this process, the rate of degassing from volcanic conduits might be controlled by the availability of the gas from the magmatic system. As a result, the rate of degassing might not be limited by the volcanic plumbing system.

On the other hand, the average void fraction showed a different behaviour in the $240 \mathrm{~mm}$ diameter column. Void fraction decreased slightly by 0.06 then it increased again by 0.07 at the last gas flow rate in this range. The difference in the void fraction between both columns at the transition to churn regime can be explained by comparing the data of the time series of void fraction in Figure 4 and 4. First, the transition to churn flow region in the smaller diameter column consists of longer bubbles of higher frequency, higher coalescence rate, and lower frequency of churn regions compared to the case in the larger diameter column. This explains the higher values of void fraction which are due to the difference in the column diameter and the small variation of viscosity in two columns. The gas volume fraction is larger in the smaller diameter column for the same gas flow rate due to the geometry. In addition, the void fraction increases with increasing liquid viscosity, Philip et al. (1990). Although the study conducted by Philip et al. was performed for bubbly and slug flows, they covered fairly wide range of highly viscous fluids (i.e. 115-300 mPa.s). Further investigation is required to study the effect of the viscosity on the void fraction of highly viscous oil (i.e. up to $300 \mathrm{~Pa}$.s) in churn flow. The percentage of churn time increases gradually with increasing gas flow rate in the smaller diameter column while it increases significantly in the larger diameter column. However, void fraction exhibits an increase at the highest gas flow rate in the smaller diameter column. This might be a beginning of fluctuation due to the significant increase in the coalescence between the bubbles before starting churn flow regime.

\subsection{Probability Density Function}

The Probability Density Function (PDF) signature is commonly used to identify the flow structure of two phase flow Costigan and Whalley (1997). PDF in combination with the time series of void fraction data extracted from the ECT was used to identify the flow structure of churn flow in high viscosity oils. Data from the void fraction time series, where long bubbles occur, was extracted from the overall time series of void fraction and separated from that in the churn regime. The PDF was calculated for each segment separately. Figure 10 compares the overall PDF (which represents the whole flow structure) with the PDFs of the churn and slug flow separately. 


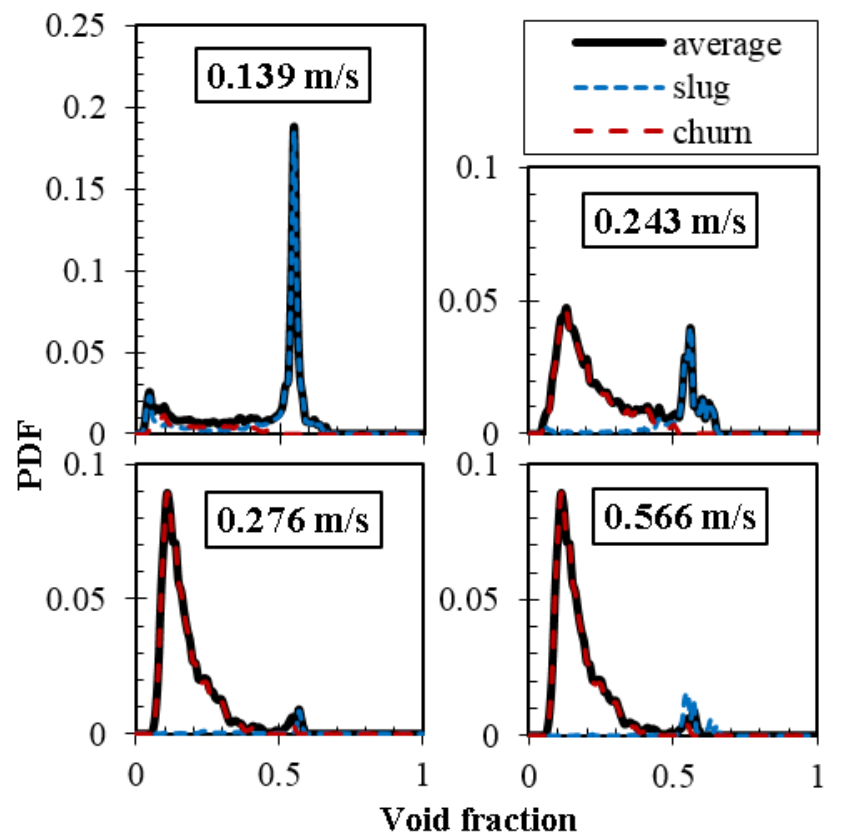

Figure 10: PDF for air flow in 330 Pa.s viscosity Silicone oil and $290 \mathrm{~mm}$ diameter column at different gas superficial velocities. The dashed lines in blue and red correspond to the slug and churn areas which were extracted from time series of void fraction of the $290 \mathrm{~mm}$ diameter column. The first two graphs at 0.139 and $0.243 \mathrm{~m} / \mathrm{s}$ gas superficial velocities which show the transition to churn flow. While the last two PDFs at gas superficial velocities of 0.276 and $0.566 \mathrm{~m} / \mathrm{s}$ show churn flow regime.

This figure can be divided into 4 parts. First, the beginning of the transition to churn flow (the lowest gas superficial velocity in the figure), when the structure contains long bubbles separated by regions of churning. At this gas flow rate, the long bubbles with high void fractions (PDF in blue) dominate the structure of the flow, while the probability of "churn" regions is still low (PDF in red). Then, with increasing gas flow rate, at the transition to churn flow, the frequency of churning regions increases. For example at a gas superficial velocity of $0.243 \mathrm{~m} / \mathrm{s}$ the PDF of the higher void fraction in blue (the long bubbles) peaks at an approximately equal value to the PDF of the lower void fraction which is the churning regions (in red). Furthermore, at the beginning of churn flow, at a gas superficial velocity of $0.276 \mathrm{~m} / \mathrm{s}$ the frequency of churning regions (PDF in red) increases dramatically with a probability of appearing in a number of long bubbles. Finally, at the higher gas flow rate, the probability of presence of churning regions is almost similar to the lower gas flow rate with the existence of one long bubble. However, at gas superficial velocities of 0.336 and $0.518 \mathrm{~m} / \mathrm{s}$ (in the churn flow range) churn regions appear to dominate the whole flow structure with no evidence of any large bubbles, see Figure 6.

317 


\subsection{Pressure gradient}

A wide range of gas superficial velocities of $0.003-0.517 \mathrm{~m} / \mathrm{s}$ was applied to study the pressure drop in the $290 \mathrm{~mm}$ diameter column at different flow patterns. Figure 11 shows a schematic drawing for the flow patterns observed in high viscosity liquids and large diameter columns. It displays the structure of gas flow in 330 Pa.s Silicone oil and $290 \mathrm{~mm}$ diameter column. Measurements of the pressure gradient were collected for each flow regime shown in this figure.

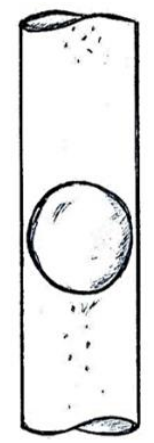

Bubbly flow

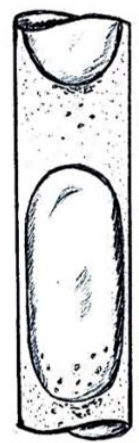

Slug flow

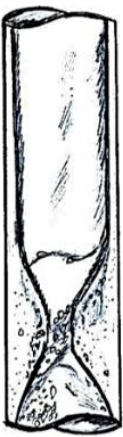

Transition to churn flow

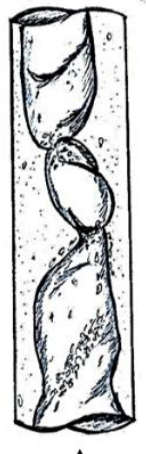

Churn flow

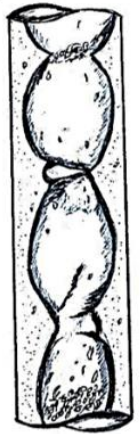

$0.171 \mathrm{~m} / \mathrm{s}$

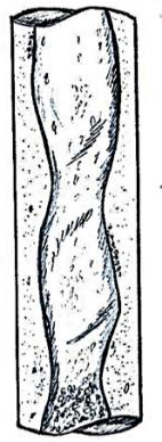

$0.566 \mathrm{~m} / \mathrm{s}$

Figure 11: Schematic drawing showing the flow patterns in $330 \mathrm{~Pa} . \mathrm{s}$ Silicone oil and $290 \mathrm{~mm}$ diameter vertical pipe. The arrows in the figure correspond to the direction of the liquid flow.

The results of the pressure gradient measurements are shown in Figure 12 came in agreement in trend with the work done by Owen (1986) who used air-water in a $32 \mathrm{~mm}$ diameter vertical pipe and presented the change of pressure gradient data against dimensionless gas velocity for a number of liquid flows in vertical pipes. According to his results, the pressure gradient values at slug region showed a sudden drop and then a sharp increase again at the slug/churn transition region due to the high frequency wave activity and friction. A similar trend in the pressure gradient values was observed in this work. As shown in Figure 12, the pressure gradient at the onset of churn region increased gradually by $2 \mathrm{KPa} / \mathrm{m}$ from 0.276 to $0.322 \mathrm{~m} / \mathrm{s}$ due to increase in frequency of the churn areas where the interaction is very intense between the oil and the air. Pressure gradient then remained almost constant until a gas superficial velocity of $0.517 \mathrm{~m} / \mathrm{s}$ was reached. The flow structure in churn flow regime was found more stable in terms of structure velocity, mean void fraction, and mean film thickness. The deviation in the pressure gradient behaviour can be attributed to the substantial difference in the liquid viscosities, surface tension, and the pipe diameters. Wallis (1962) found that during the start of churn flow, entrainment of the droplets occurs from the large 
liquid fractions which travel as large flooding waves along the column. This mechanism of churn flow formation is not applicable for high viscosity liquids such as the oils used in the present work. No droplets were observed in the 330 and 360 Pa.s Silicon oils due to the very high viscosity.

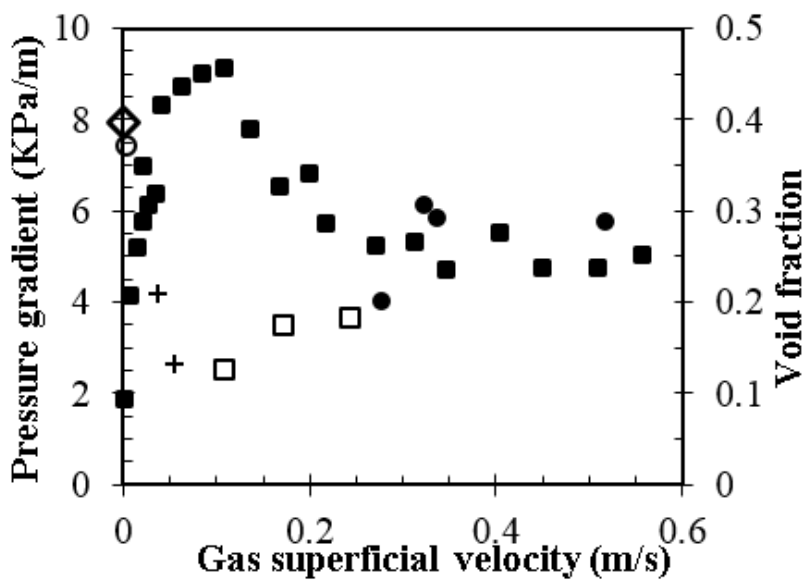

Figure 12: Mean pressure gradient and mean void fraction with changing the flow patterns of air flow in $330 \mathrm{~Pa}$. Silicone oil and $290 \mathrm{~mm}$ diameter column. $\odot \mathrm{dP}$ in bubbly, $+\mathrm{dP}$ in slug, $\bullet \mathrm{dP}$ in churn, $\diamond$ stagnant, $\square \mathrm{dP}$ in transition to churn, $\square$ void fraction.

Figure 13 illustrates the changing in pressure with time in air-viscous oil mixture in $290 \mathrm{~mm}$ diameter column for different gas flow rates. Pressure starts to fluctuate steadily during slug flow at slug flow regime. This is due to the high frequency of the long Taylor bubbles which occupy a significant portion of the cross-sectional area of the column. The fluctuation of the pressure outputs reaches the maximum due to the increase in the frequency of the liquid bridges (churn regions) during transition to churn flow. The pressure gradient in churn flow can be seen in the last four flow rates. The oscillation in pressure decreases gradually for increasing gas flow rates; this potentially is due to the thick film around the air conduit in the column. The uniform pressure drop downstream the ECT (see Fig. 13, for gas superficial velocities Ugs= $0.276,0.332,0.336$ and $0.517 \mathrm{~m} / \mathrm{s}$ ) indicates that the fully developed flow is achieved. Such uniformity can also be seen from the void fraction data (at Ugs $>0.276 \mathrm{~m} / \mathrm{s}$ ) obtained from the ECT and already displayed in Figure 12. In addition, a series of high quality videos reveal that the characteristics of the churn flow are exist. 


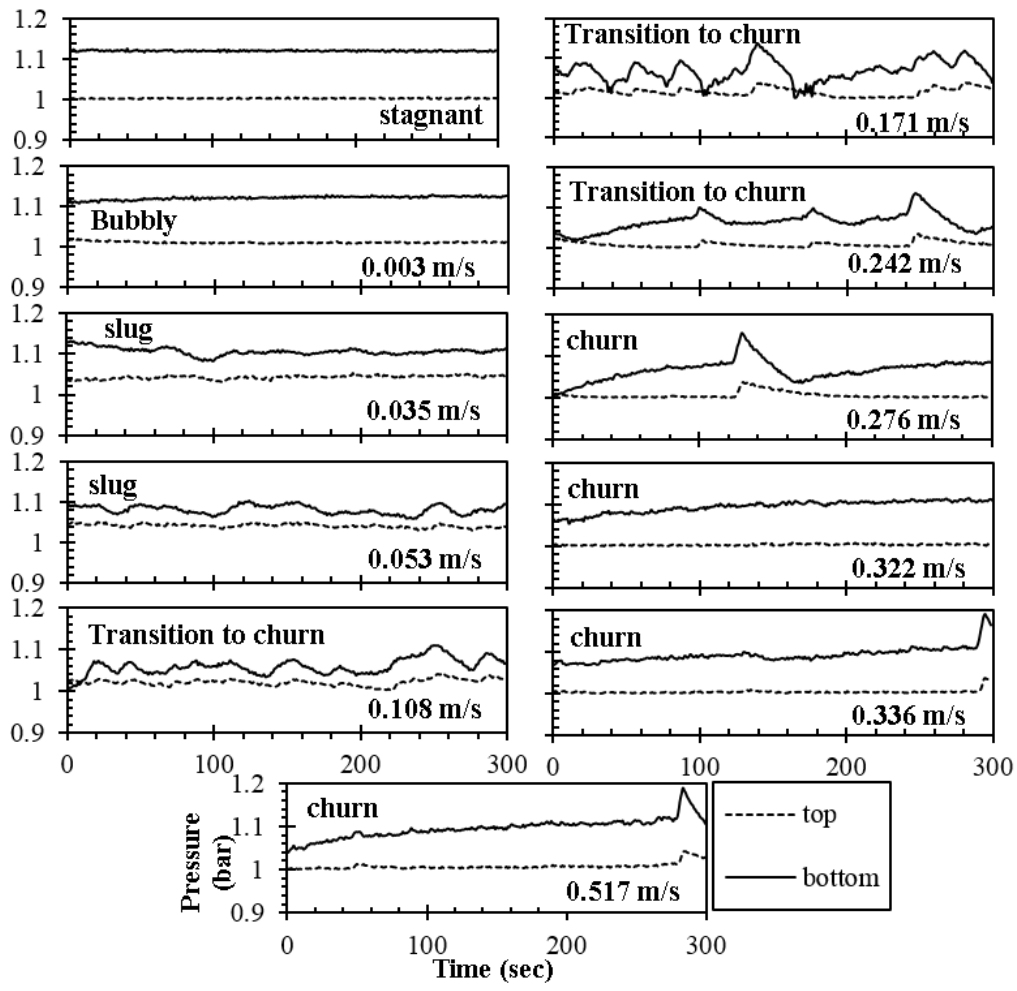

360 Figure 13: Effect of gas-viscous oil flow on the pressure inside the $290 \mathrm{~mm}$ diameter column for different gas flow rates. The distance between the two sensors is $1.4 \mathrm{~m}$, the bottom sensor is located at $2.2 \mathrm{~m}$ from the gas inlet section.

\subsection{Motion, Dimensions and Structure of the Flow}

Structure velocity, length of long bubbles and frequency have been determined in the transition to churn and in the churn flow regimes in high viscosity oils and large diameter columns. They have been calculated from the time series data of void fraction obtained from the ECT. Structure velocity was calculated by cross-correlating the void fraction signal from both ECT planes. Figure 14 illustrates the effect of increased gas flow rate on the structure velocity. In general, structure velocity increases with increasing gas flow rate in both columns at the transition to churn flow regime. It increased by $0.56 \mathrm{~m} / \mathrm{s}$ in the larger diameter column and $0.33 \mathrm{~m} / \mathrm{s}$ in the smaller diameter column. While no considerable increase was seen in churn flow regime in the larger diameter column. structure velocity is lower in the smaller diameter column because the large bubbles are longer and the rate of coalescence is higher. On the other hand, structure velocity in churn flow regime showed an increase of $0.02 \mathrm{~m} / \mathrm{s}$ in the $290 \mathrm{~mm}$ diameter column, potentially due to the oscillating movement of the liquid bridges in this flow regime. The slight fluctuation in the values of the void fraction at this flow regime is caused by the single bubble that appears at some gas flow rates. 


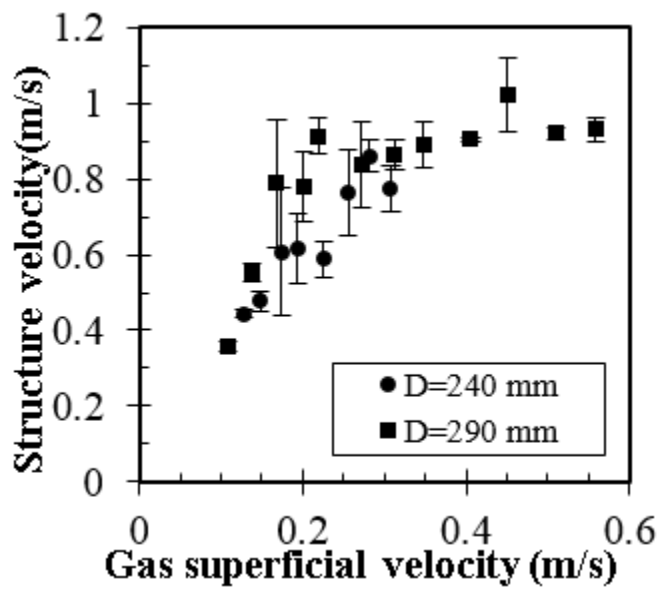

Figure 14: The structure velocity of gas flow in 360 and $330 \mathrm{~Pa}$.s Silicone oil and 240 and $290 \mathrm{~mm}$ diameter respectively at the transition to churn flow and churn flow regimes. The maximum standard errors calculated for the structure velocity are $16 \%$ and $9 \%$ for the 240 and $290 \mathrm{~mm}$ diameter columns respectively.

The experimental structure velocity was compared with a theoretical approach by Viana et al. (2003) and Guet et al. (2004) in Figure 15. The rise velocity of Taylor bubble $U_{T B}$, which bridges the pipe cross section area in stagnant liquid, was determined both theoretically and experimentally by Davies and Taylor (1950) and Nicklin (1962). $U_{T B}=F_{r} \sqrt{g D_{B}}$, where: $D$ is the pipe diameter, $g$ is the gravitational acceleration and $F_{r}$ is Froude number, a dimensionless velocity represents the ratio of the gravitational and inertial forces which are equal to 0.351 and 0.328 . These values are constants proposed by Dumitrescu (1943) and Davies and Taylor (1950) to represent $F_{r}$. Dumitrescu (1943) proposed $F_{r}$ equal to 0.351 for the first time analytically. Then, Davies and Taylor (1950) presented a value of 0.328 analytically and experimentally. Viana et al. (2003) presented an equation to determine the value $F_{r}$ basing on the dimensionless inverse velocity Buoyancy Reynolds number, $R . R=\sqrt{D_{B}^{3}} g\left(\rho_{l}-\rho_{g}\right) \rho_{l} / \mu$, and Eötvös number, $E_{o}$ which is the ratio of the interfacial tension and viscous forces; $E_{o}=g \rho_{l} D_{B}^{2} / \sigma$. Where $\mu$ is liquid viscosity, $\sigma$ is surface tension and $\rho_{l}$ and $\rho_{g}$ are densities of the liquid and the gas respectively. They also presented a universal correlation for the flat region of high Buoyancy Reynolds number and inclined region of low Buoyancy Reynolds number. These two regions are separated by a transition region $(10<\mathrm{R}<$ 200), which was described by fitting the data to a "logistic dose curve", the equation has 13 empirical constants. The accurate values of $F_{r}$ were shown by Viana et al. (2003) and Azzopardi et al. (2014) for liquids up to 300 Pa.s viscosity. 

by the following relationship, Nicklin (1962);

$$
U_{T B}=C_{o}\left(U_{g s}+U_{l s}\right)+K F_{r} \sqrt{g D_{B}} .
$$

$U_{g s}$ and $U_{l s}$ are gas and liquid superficial velocities respectively, $K=0.905 /\left(1-\varepsilon_{g s}\right)^{3.95}$. The

coefficient $C_{o}$ represents the ratio of the maximum centreline velocity of the bubble to the mean upward liquid velocity. Nicklin (1962) suggested a value of 1.2 for the coefficient $C_{o}$. Collins et al. (1978) suggested a slight modification of Nicklin (1962) relationship, basing on a strong theoretical support. He suggested a value of 1.29 for $C_{o}$. In Equation 12.25 the difference between the two $C_{o}$ values is due to the difference of pipe diameters. However, according to Nicklin (1962) the higher values of $C_{o}$ are more suitable when the flow rates decrease. Another study by Dukler and Fabre (1994) and Guet et al. (2004) proposed more complicated equation for $C_{o}$ value. It can be written as:

$C_{o}=\frac{C_{B c}}{\left[1+\left(\frac{R_{e m}}{R_{e c}}\right)^{2}\right]}+\frac{C_{0, R e=\infty}}{\left[1+\left(\frac{R_{e c}}{R_{e m}}\right)^{2}\right]}$ $290 \mathrm{~mm}$ diameter columns respectively at the transition to churn flow regime.

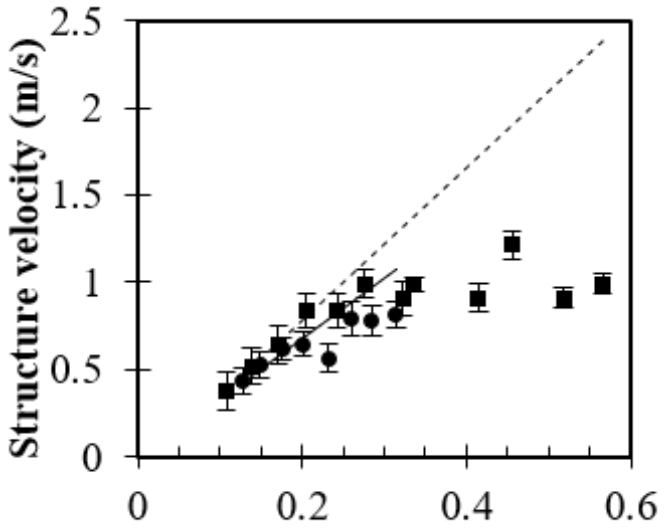

Gas superficial velocity $(\mathrm{m} / \mathrm{s})$

Figure 15: Theoretical and experimental large bubbles velocities in viscous Silicone oil for both columns. -:240mm, - 290mm (experimental) and — 240mm, ---290mm (from Viana et al. (2003), and Guet et al. (2004), using $C_{B C}=2.27$ ).

However, in the smaller diameter column, the ECT measurement fluctuation is due to the increasing coalescence rate between the bubbles. The calculated and experimental structure velocities show a big 
divergence in the churn flow regime (relative error of 1.3). The models used in these predictions are not applicable for churn flow regime, as slip velocity is calculated based on the velocity of large bubbles.

The length of the large bubbles was calculated from the structure velocity and the time of the bubble passing through the ECT electrodes. The length of large bubbles flow in high viscosity liquids and two large diameter columns are displayed in Figure 16. In general, large bubble length increased significantly with increasing gas flow rate in the transition to churn flow region. Whereas, it decreased in the churn flow regime in the $290 \mathrm{~mm}$ column. Also, bubble length is higher in the smaller diameter column for the most of the gas flow rates.

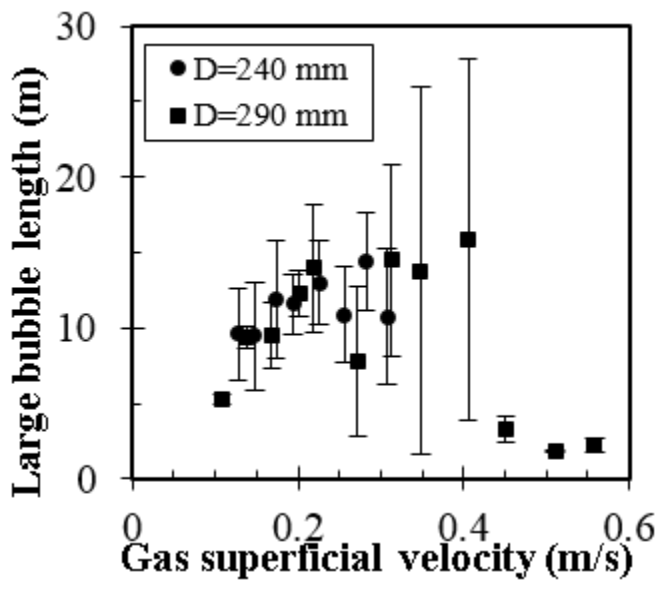

Figure 16: Lengths of the large bubbles in viscous oil and large diameter columns at the transition to churn flow and churn flow regimes.

In the $290 \mathrm{~mm}$ diameter column, the bubbles length increases significantly from 5.2 to $13.9 \mathrm{~m}$ when the gas superficial velocity is increased from 0.108 to $0.243 \mathrm{~m} / \mathrm{s}$ (transition to churn flow regime). While it increases gradually from 9.5 to $14.4 \mathrm{~m}$ for gas superficial velocity increase from 0.127 to $0.314 \mathrm{~m} / \mathrm{s}$ (churn flow). These high values of the bubble lengths are due to the high rate of coalescence between the bubbles which produces a very long bubble. At the same time, the frequency of bubbles decreases due to the increasing frequency and length of the churn regions. It in turns increases due to the increasing fraction of liquid draining from the very long bubbles. The bubbles' length which appears in the figure is higher than the length of the column at certain gas flow rates. Some large bubbles that burst at the top section of the column in this flow regime remain as an open core for some time. The length of the bubble is calculated from the time of the bubble passing through the ECT sensor, therefore open core can be considered a very long bubble. This long bubble is not a Taylor bubble as it contains large waves on the falling film and does not have a rounded top and/or bottom as the Taylor bubbles that appear in slug flow. 
flows. This is due to the complicated structure in this flow regime which consists of an open gas core with liquid bridging of varying film thicknesses and a possibility of creating a very long bubble and leads to an error of $122 \%$ for the $290 \mathrm{~mm}$ diameter column. The maximum standard error for the bubble length calculated for the smaller diameter column is $14 \%$. the number of bubbles over the gas injection time. Unlike bubble length, the frequency of the bubbles appears to decrease with increasing gas flow rate in the transition to churn flow region. In the larger diameter column, the frequency decreases approximately by $0.023 \mathrm{~Hz}$ in the transition to churn flow region. This can be attributed to the increasing length of bubbles due to bubble coalescence. In the churn flow regime, frequency increases by $0.113 \mathrm{~Hz}$. See Figure 17.

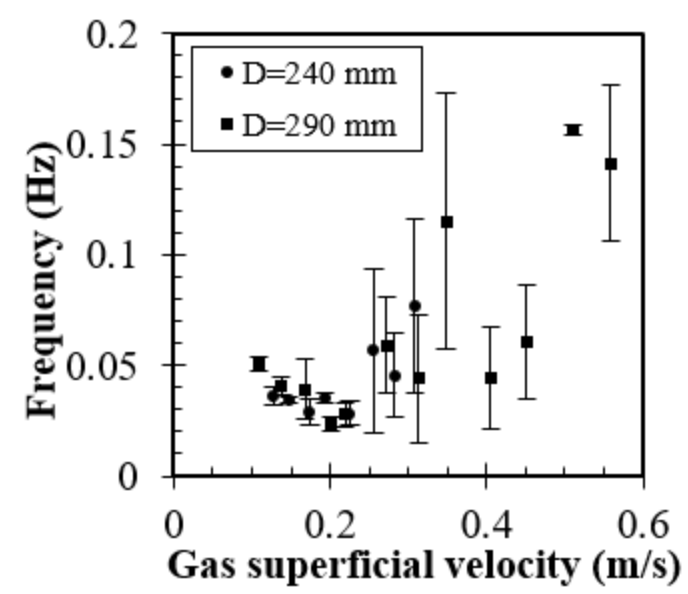

Figure 17: Frequency of the large bubbles at the transition to churn flow and churn flow regimes in high viscosity liquids and large diameter columns. The maximum errors are $3.9 \%$ and $5.7 \%$ for 240 and 290 mm diameter column.

. When the time series of void fraction are used to determine the bubble frequency it appears that bubble frequency increases when there is only one long bubble appearing in the void fraction signal at the same flow rate range. This is potentially due to the increase in the frequency of liquid bridges that behave like a series of bubbles connected to each other. Therefore, in the transition to churn flow region, the dominant frequency represents the frequency of long bubbles which decrease with increasing gas input. While in churn flow the dominant frequency represents that of short bubbles produced by liquid bridging which increases with increasing gas flow rate. 
Phase distribution images for the cross-sectional of the column of air and 330 Pa.s Silicone oil in $290 \mathrm{~mm}$ diameter were reconstructed using the ECT32 and Recon commercial software that incorporate the iterated Tikhonov regularisation technique. The structure of flow in such viscous oils was studied by comparing the time series of void fraction, film thickness, and the reconstructed images of the phase distribution inside the column. The average film thickness in the transition to churn and in churn flow regions was determined in the 240 and $290 \mathrm{~mm}$ diameter columns. It was calculated by the geometric relationship $\delta=(\mathrm{D} / 2)\left(1-\sqrt{\varepsilon_{\mathrm{g}}}\right)$, where $\delta$ is the film thickness, $\varepsilon_{\mathrm{g}}$ is the void fraction from the ECT. The film thickness was estimated in both flow regimes using the void fraction data collected from the two ECT planes. fraction and the calculated film thickness for churn flow in the $290 \mathrm{~mm}$ diameter column. The Tikhonov generate the reconstructed images. The three plots are at the same flow rate and the same time period. In Figure 18, the phases' distribution in the cross section from the upper plane of the ECT is displayed at different time instances. They have been generated using the ECT32 software at $0.566 \mathrm{~m} / \mathrm{s}$ gas superficial velocity. The red colour corresponds to the high permittivity fluid which is the 330 Pa.s Silicone oil and the blue colour corresponds to the low permittivity fluid, the air. The green and the yellow colours represent the interface between the two fluids. B1, B2, A1, and A2 in the figure refer to a time or sections. For example, A1 presents the phase distribution of the large bubble at $120 \mathrm{~s}$. It also refers to the corresponding void fraction, film thickness, and the reconstructed image. The churning regions exist between 3 and 100 $\mathrm{s}$, corresponding to B1 and B2 in these two figures. Also, (B) at 350 and $500 \mathrm{~s}$ for the time series in Figure 4 , at the same flow rate. The gas core in churn flow regions seems to change its location from the centre to near the wall of the column unlike the case for low viscosity liquids where it always exists in the centre of the pipe. For example, the gas core in B1 is next to the column's wall while in B2 is almost at the centre of the column. This also can be seen clearly from the photos of the column in Figure 6. This might be due to the effect of the very high viscosity and the low surface tension $(0.02 \mathrm{~N} / \mathrm{m})$ which can be negligible in very high gas flow rates (Snabre and Magnifotcham, 1998). 


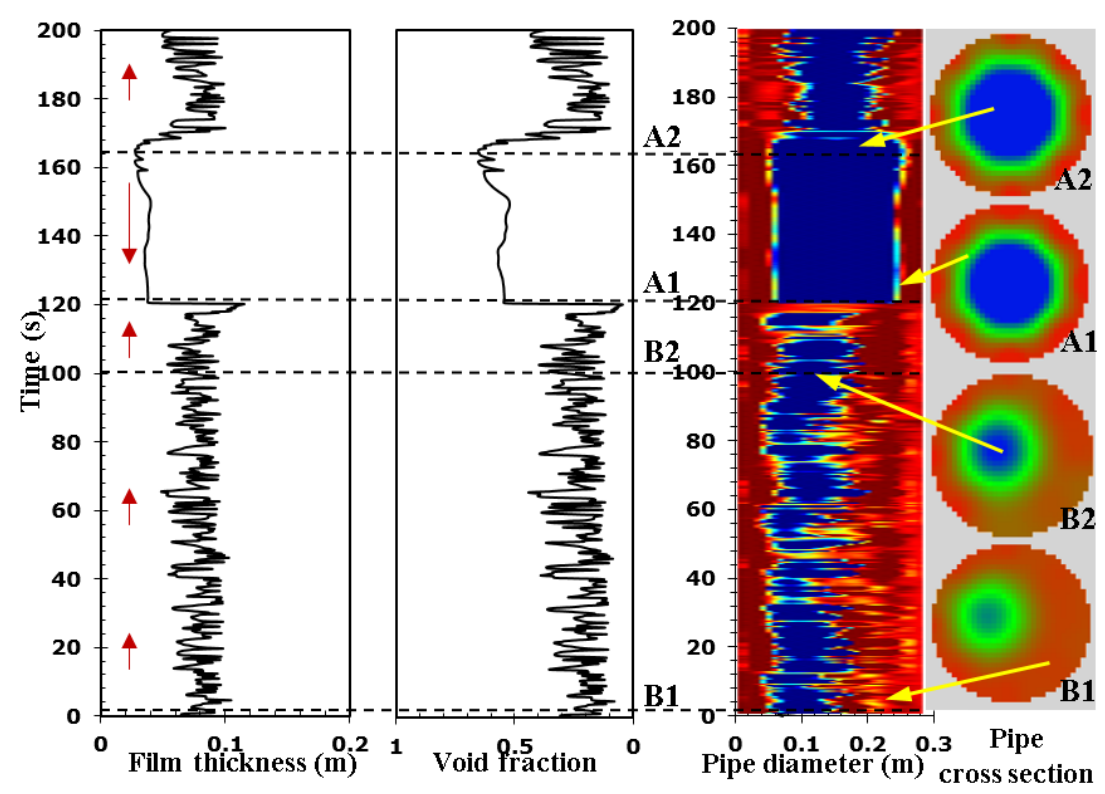

496 Figure 18: Film thickness, void fraction, the reconstructed image using Tikhonov regularisation technique with 100 iterations and the pipe cross section for gas flow in 330 Pa.s Silicone oil and $290 \mathrm{~mm}$ diameter difference between this large bubble and the Taylor bubbles in classical slug flow regime is the top and the bottom shape of the bubbles. Large bubbles have almost a flat top and end and separated from the churn regions by a thin film. The length of these large bubbles in churn flow regime seem to be dependent on the gas flow rate. This very long bubble represents the open core with the falling liquid film, B in Figure 7.

The liquid film in churn flow varies in direction and thickness in both sections $\mathrm{A}$ and B. The liquid

film surrounding the large bubbles flows downward to merge with the liquid travelling upwards in the following churn region. While the film in the churn region flows in different directions and rests at some points. The average film thickness seems to decrease slightly at the same gas flow rate, this will be discussed in the next section.

Figure 19 and Figure 20 show the film thickness of gas flowing in 330 Pa.s Silicone oil and $290 \mathrm{~mm}$ diameter column at two different flow regimes. The first figure is the transition to churn flow at a gas superficial velocity of $0.243 \mathrm{~m} / \mathrm{s}$. 


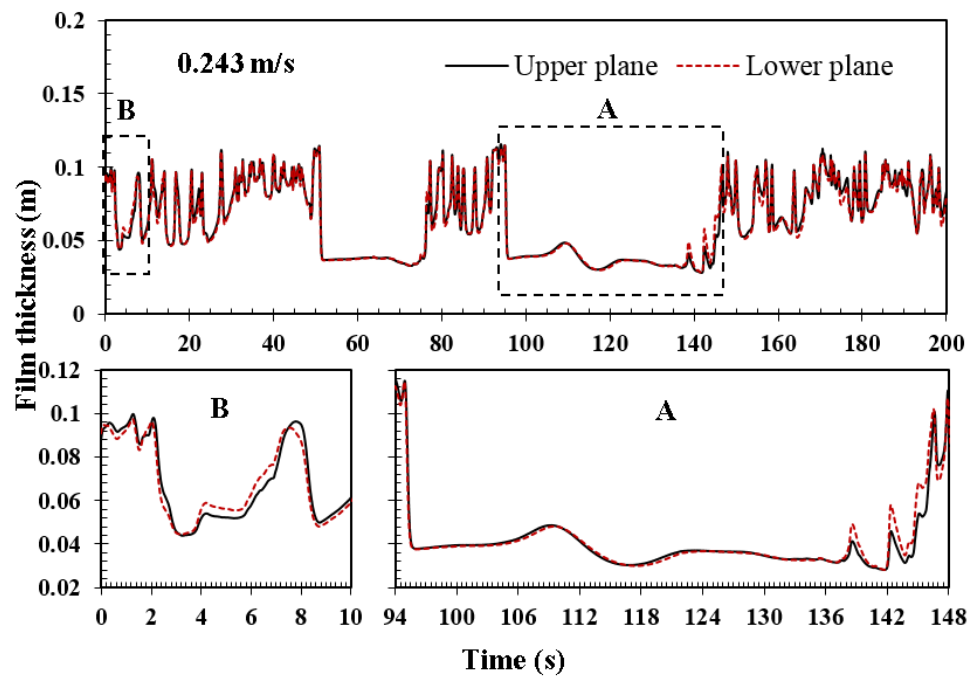

Figure 19: Film thickness at the transition to churn flow in $330 \mathrm{~Pa} . \mathrm{s}$ and 290 diameter column at a gas superficial velocity of $0.243 \mathrm{~m} / \mathrm{s}$.

The second figure (Figure 20) is at a gas superficial velocity of $0.566 \mathrm{~m} / \mathrm{s}$ which represents the film thickness in churn flow regime. In both figures, $200 \mathrm{~s}$ length of data is presented at acquisition frequency of $50 \mathrm{~Hz}$. Both figures focus on the direction of the film in the large bubble and the churn sections. In the ECT sensor, the electrodes in plane 1 are located above the ones in plane 2. This makes the value of wave's velocity positive when they pass from plane 2 (lower plane) first.

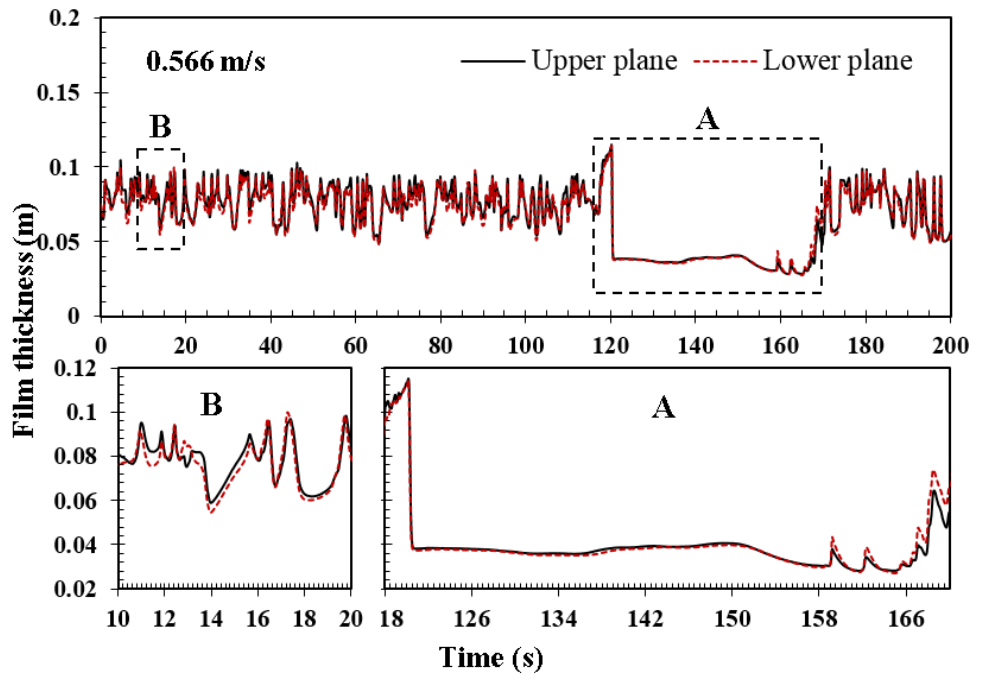

Figure 20: Film thickness at churn flow in 330 Pa.s and 290mm diameter column at a gas superficial velocity of $0.566 \mathrm{~m} / \mathrm{s}$.

The values of the wave velocities were calculated from the time delay of each wave and the distance between the two planes. Velocity is equal to the distance between the planes $(0.036 \mathrm{~m}$ in this sensor $)$ divided 
by the difference in time. Similarly, if the values of the calculated wave velocity are negative, this indicates downward film flow. Since the wave passes through the upper plane P1 first then to the lower plane P2.

In general, the liquid film flow shows an average of downward movement in the large bubbles area (A in both figures) and upward flow in churn flow region (B) with some difference. Starting with the direction of liquid flow in the large bubbles (A) in both flow regimes (both figures). The waves' velocity showed negative values (downward flow) for all the waves in churn flow while it showed some upward flow in the transition to churn flow regime. For example, the calculated velocities for the wave on the film around the large bubble at the transition to churn flow were $-0.078,-0.052,0,0.3$, and $0.3 \mathrm{~m} / \mathrm{s}$ at about 107 , $120,138,142$, and $146 \mathrm{~s}$ respectively. The velocity and the direction of the flow are not constant in this flow regime. The film flows downward between about 94 and $130 \mathrm{~s}$. Then there is a time when the liquid holds/stagnates (between about 137-140 s) before it changes direction flowing upward from about 142 to $146 \mathrm{~s}$. This area is followed by churn section. This upward direction for the film around the large bubble might be due to the development of this fraction to churn.

Different behaviour is exhibited by the liquid film around the large bubble (A) in the churn flow is shown in Figure 20. In this flow regime, the calculated velocities of the waves were $-0.045,-0.075,-0.22$, $0,-0.225 \mathrm{~m} / \mathrm{s}$ and hold at about $136,152,159,162,166$, and $168 \mathrm{~s}$ respectively. This provides an evidence of the downward direction of movement of the film around the large bubble.

The following churn section in churn flow regime did not show a significant effect on the direction and velocity of the film around the large bubble at the bottom. This might be due to the structure of flow in churn flow regime which seems to be more stable in terms of structure velocity, mean void fraction and mean film thickness. The wave velocities in the transition to churn flow and churn flow regimes were less than the values reported by Benjamin (1957). This can be referred to the very high viscosity of the liquid employed in this study. Benjamin studied the characteristics of the stability of laminar stream of viscous falling film on an inclined plane. According to his analysis, the velocity of the wave was equal to $-3 U_{f}$ for liquid film Reynolds number equal to $0 . U_{f}$ is the velocity of the falling film.

The film thickness in churn sections -(B) in both flow regimes- shows different values in film thickness and directions compared to that in large bubbles. In general, the direction of flow fluctuates between upward and liquid stagnation in churn flow regime, and upward flow in the transition to churn flow regime. The waves' velocity in the transition to churn flow is higher than the ones registered in churn flow. They vary from $0.22,1.8,4$, and $0.1 \mathrm{~m} / \mathrm{s}$ at about $0.2,1.2,2$, and $8 \mathrm{~s}$ respectively, Figure 19 . While in 
churn flow regime in Figure 20. The wave velocities were 0.6, 0, 0, 0, 0.3, and 0.9 at about 11, 12.4, 15.6, 17 and $19.7 \mathrm{~s}$ respectively. These times of liquid holding agree with the visual observation as the gas seems to move as pulses during experiments.

Comparing these results of the film thickness, reconstructed images and the photographs of these two flow regimes show two different flow characteristics. Both consists of two sections, one contains large bubbles which differ from Taylor bubbles but has a thin falling film. And second, sections of highfrequency activity of liquid bridges with a thick film travelling in different directions. These two flow regimes can be distinguished by the frequency of the high activity sections (churn) which increases with increasing the gas flow rate. Also by the decrease of frequency of large bubbles with increasing gas input. Then, at a specific gas flow rate, the flow structure changes significantly (at $0.276 \mathrm{~m} / \mathrm{s}$ gas superficial velocity). The flow at this gas flow rate is dominated almost completely by high-frequency liquid bridging. A single large bubble might appear in a number of gas flow rates. Therefore, the flow regime from the gas superficial velocity of $0.108-0.243 \mathrm{~m} / \mathrm{s}$ can be characterised as a transition to churn flow. While the flow regime from the gas superficial velocity of $0.276-0.566 \mathrm{~m} / \mathrm{s}$ is churn flow, refer back to the time series of void fraction plots in Fig. 6. The liquid film motion directions in churn areas are upwards and stagnation as indicated by the holdup which in turn refer to flooding. However, the waves in the flooding regions are not always showing the holdup effectively.

Seemingly, one of the known mechanisms for the transition to churn flow regime is flooding of the liquid film which occurs in slug flow inside the Taylor bubbles (Jayanti and Hewitt (1992) and Jayanti et al. (1993)). Govan et al. (1991) proposed that the transition to churn flow regime occurs due to the generation of "flooding-type wav". They also assumed the existing of the strong relation between churn flow and flooding phenomenon. The difference between the present work and the previous works from literature is the much larger pipe diameter and the much higher viscosity. For example, the droplets which from the breaking up of the flooding waves that occur in low viscosity liquids were not observed in the present study. In such high viscosity, no entrained fractions of liquid were found due to the very high viscosity of the oil.

Figure 21 displays the effect of increasing the gas flow rate on average film thickness in the transition to churn and churn flow regimes. In general, gas flow rate shows more effect on film thickness in the larger diameter column and also a change in the trend of the liquid film between the two flow regimes appears clearly in the larger diameter column. However, the film thickness in the smaller diameter column 
represents only one flow regime (the transition to churn flow). In addition, in the larger diameter column, the film thickness increased gradually by $0.2 \mathrm{~m}$ in the transition to churn flow regime while it increases slightly by only $0.005 \mathrm{~m}$ in the $240 \mathrm{~mm}$ diameter column. This increase in the film thickness values might be caused by the increasing frequency of the liquid bridges (churn) which have higher film thickness compared to the large bubbles region. Then when comparing the time series data in Fig. 5 and 6, the frequency of the churn regions is higher in the larger diameter column. This explains the difference between the trends in both columns. Also, in the larger diameter column, the frequency of the churning regions increases significantly in the transition to churn flow regime while it exhibits a slight increase in the smaller diameter column. This corresponds to the film thickness values in Figure 21.

In the churn flow regime, starting from $0.276 \mathrm{~m} / \mathrm{s}$ gas superficial velocity in the $290 \mathrm{~mm}$ diameter column, the film thickness appears to be more stable. It increases by only $0.003 \mathrm{~m}$ over a wide range of gas flow rates. This can be related to the time series data in Figure 6 and 6. The mean film thickness can also be linked to with Figure 9 the averaged void fraction. The maximum errors are $0.76 \%$ and $0.35 \%$ for the 290 and $240 \mathrm{~mm}$ diameter columns respectively.

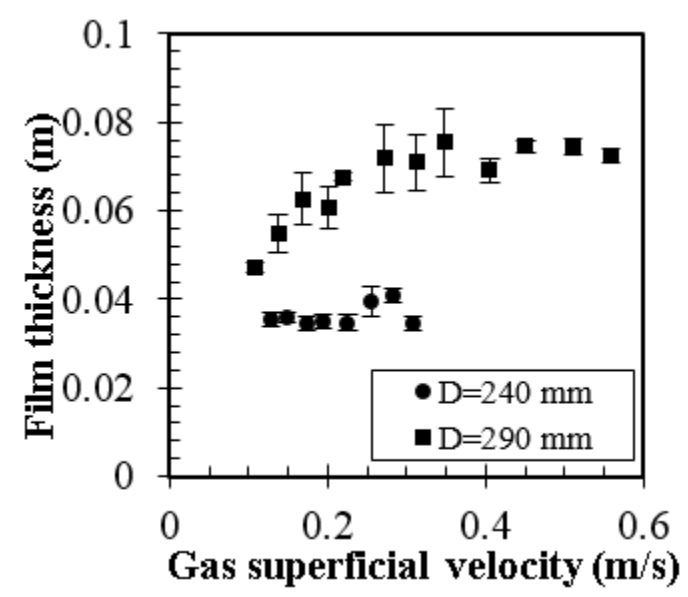

Figure 21: Averaged film thickness around the gas passing through 360 and 330 Pa.s Silicone oil in 240 and $290 \mathrm{~mm}$ diameter columns respectively at the transition to churn flow and churn flow regimes. The error bars represent the standard error for the film thickness values.

\subsection{Oscillations at the Top Section}

The height of the liquid in the column was recorded at a gas superficial velocity of $0.178 \mathrm{~m} / \mathrm{s}$ for 10 min at four different times over $5.5 \mathrm{~h}$ of the gas injection. In this experiment, the gas was injected for $5.5 \mathrm{~h}$ at a constant flow rate to study the effect of the gas injection time on the flow structure in 330 Pa.s Silicone oil. Figure 22 shows the top surface height obtained at four different times during 5.5 hours of constant gas 

surface oscillation corresponds to the eruption of long bubbles shown in the time series of void fraction.
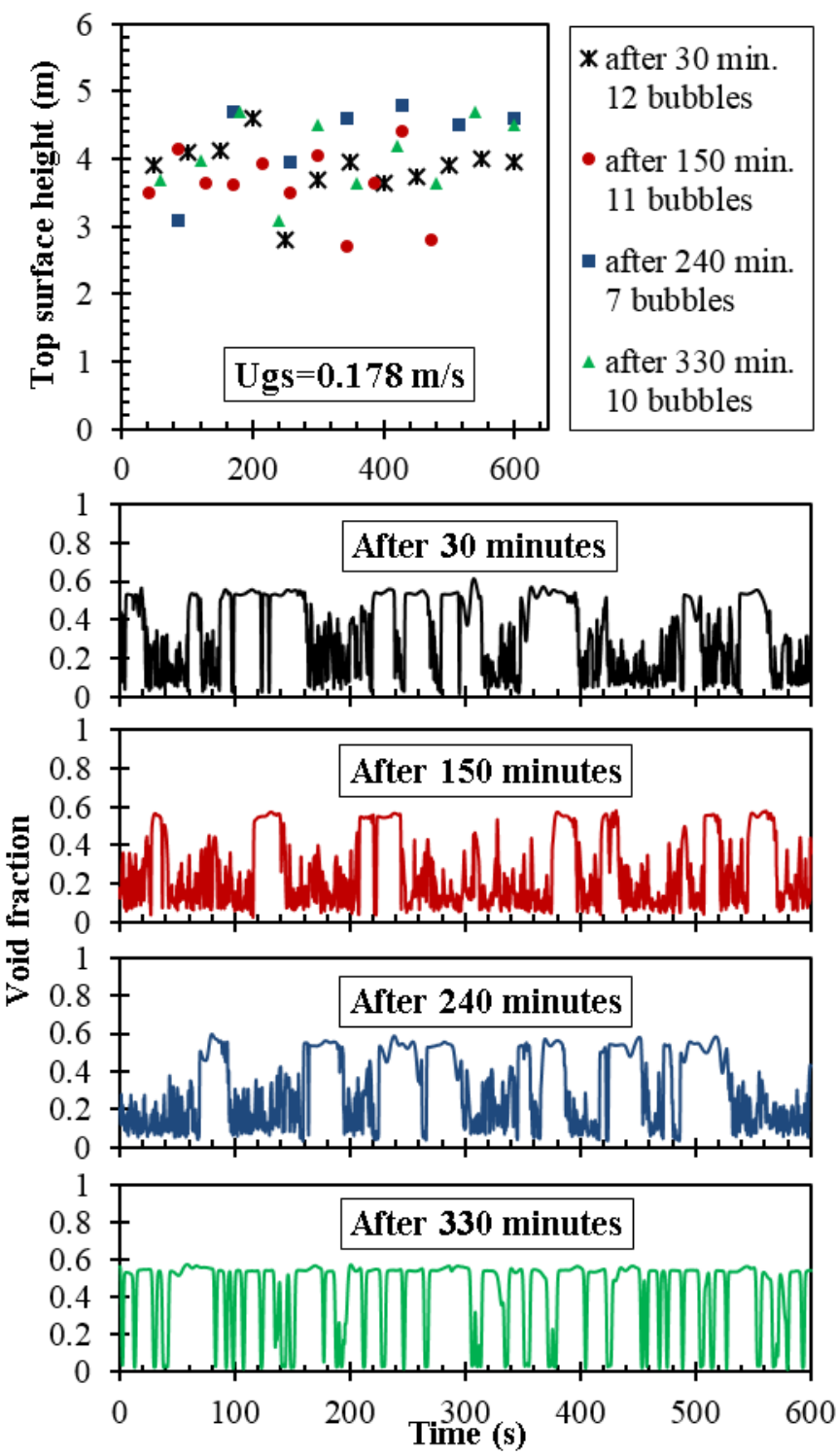

Figure 22: The change of the position of the top surface (liquid height per single bubble) during the time for constant gas superficial velocity in four different times during the day in $290 \mathrm{~mm}$ diameter column. The colours of the time series of void fraction correspond to the height of the top surface for each time.

The liquid height oscillates periodically in the data collected at 150 and $330 \mathrm{~min}$ from the start of the injection, while a different trend was obtained in the data collected at 30 and $240 \mathrm{~min}$. This is due to the unstable structures in the transition to churn flow. It also might belong to the uncertainty of locating the liquid height due to the presence of liquid film on the pipe wall from the previous bubble's eruption.

The difference in the average heights of the top surface of the $5.5 \mathrm{~h}$ is $140 \mathrm{~mm}$. This is due to the increase in the concentration of the trapped small bubbles (centimetres-millimetres bubbles) in the column 
which also contribute to increasing the average void fraction as it shown earlier. The fluctuation of the top surface decreases slightly from 1.8 to $1.6 \mathrm{~m}$ from 30 to $330 \mathrm{~min}$. The reason behind that can be stemmed from the time series of the 330 minutes where the structure of the flow seems more organised. It reflects a lower rate of bubble coalescence.

\section{Conclusion}

The churn flow regime in high viscosity liquids has been studied in two large diameter columns over a wide range of gas flow rates. ECT was employed to reconstruct the image of phase distribution of airSilicone oil of 330 and 360 Pa.s viscosities. Results from the present work can be concluded as:

- The transition to churn flow regime appeared in the range of gas superficial velocities between 0.127$0.314 \mathrm{~m} / \mathrm{s}$ and $0.108-0.243 \mathrm{~m} / \mathrm{s}$ in the 240 and $290 \mathrm{~mm}$ diameter columns respectively. Churn flow regime was observed in the larger diameter column at a gas superficial velocity range of $0.276-0.566$ $\mathrm{m} / \mathrm{s}$.

- The transition to churn flow regime starts when the length and frequency of the regions of the high frequency activity, which appears at the end of slug flow regime, increases. These regions can be described as liquid bridges flowing upwards and then stagnates.

- The liquid flow shows an average downward flow movement as a film in the large bubbles areas and upward flow as large waves/bridges in the churn regions. The direction of the flow fluctuates between upwards and liquid stagnation in churn flow regime, and upwards in transition to churn flow regime.

- With increasing the gas flow rate, the length of Taylor bubbles increases producing a larger fraction of liquid film falling downwards which leads to increase in the length of churn areas.

- With increasing the gas flow rate, where the transition to churn starts to appear, pressure gradient starts to increase and void fraction to decrease due to the increase of the liquid film thickness around the air conduit in the column.

- From the results of pressure drop presented in this paper, the pressure gradient behaviour is mainly due to the void fraction effects on the total pressure drop.

- The averaged void fraction seems to decrease with increasing gas flow rate in both columns due to the increase of the frequency of churn units that have a low void fraction. In the $290 \mathrm{~mm}$ diameter column, the mean void fraction continues to decrease at the transition to churn flow until it stabilises in churn flow. 
- The structure velocity increases with increasing gas flow rate in both columns in the transition to churn flow regime.

- Bubble velocity increases with increasing gas flow rate at the transition to churn flow regime. Then no considerable increase was seen at churn flow regime. No fine bubbles were observed flowing in this flow regime.

- The length of large bubbles increases significantly with increasing gas flow rate in the transition to churn flow region. Whereas, it decreases in the churn flow regime in the $290 \mathrm{~mm}$ diameter column. Also, the length of the bubbles appears to be higher in the smaller diameter column for most of the gas flow rates.

- The droplets caused by the breaking up of the flooding waves which occur in low viscosity liquids and the MEMPHIS EPSRC (EP/K003976/1) programme. 
ABDULKAREEM, L. A. 2011. Tomographic investigation of gas-oil flow in inclined risers. The University of Nottingham.

AL- OUFI, F. M., CUMMING, I. W. \& RIELLY, C. D. 2010. Destabilisation of homogeneous bubbly flow in an annular gap bubble column. The Canadian Journal of Chemical Engineering,88,482490.

AZZOPARDI, B., ABDULKAREEM, L., ZHAO, D., THIELE, S., DA SILVA, M., BEYER, M. \& HUNT, A. 2010. Comparison between electrical capacitance tomography and wire mesh sensor output for air/silicone oil flow in a vertical pipe. Industrial \& Engineering Chemistry Research, 49, 88058811.

AZZOPARDI, B. \& WREN, E. 2004. What is entrainment in vertical two-phase churn flow? International journal of multiphase flow, 30, 89-103.

AZZOPARDI, B. J., PIOLI, L. \& ABDULKAREEM, L. A. 2014. The properties of large bubbles rising in very viscous liquids in vertical columns. International Journal of Multiphase Flow, 67, 160-173.

BARBOSA JR, J. R., GOVAN, A. H. \& HEWITT, G. F. 2001. Visualisation and modelling studies of churn flow in a vertical pipe. International Journal of Multiphase Flow, 27, 2105-2127.

BENJAMIN, T. B. 1957. Wave formation in laminar flow down an inclined plane. Journal of Fluid Mechanics, 2, 554-573.

BRAUNER, N. \& BARNEA, D. 1986. Slug Churn Transition in Upward Gas-Liquid Flow. Chemical Engineering Science, 41, 159-163.

BYARS, M. 2001 Developments in Electrical Capacitance Tomography. Keynote review, 2nd World Congress on Industrial Process Tomography (WCIPT-2), Hannover, Germany.

COLLINS, R., DE MORAES, F., DAVIDSON, J. \& HARRISON, D. 1978. The motion of a large gas bubble rising through liquid flowing in a tube. Journal of Fluid Mechanics, 89, 497-514.

COSTIGAN, G. \& WHALLEY, P. 1997. Slug flow regime identification from dynamic void fraction measurements in vertical air-water flows. International Journal of Multiphase Flow, 23, 263-282.

DAVIES, R. \& TAYLOR, G. 1950. The mechanics of large bubbles rising through extended liquids and through liquids in tubes. Proceedings of the Royal Society of London. Series A. Mathematical and Physical Sciences, 200, 375-390.

DE CACHARD, F. \& DELHAYE, J. 1996. A slugh-churn flow model for small-diameter airlift pumps. International journal of Multiphase Flow, 22, 627-649.

DE CARVALHO, J. \& FERREIRA, M. 2000. Pressure drop in gas slugs in vertical tubes and flooding instability. AIChE Journal, 46, 707-723.

DUBOSClARD, G., DONNADIEU, F., ALLARD, P., CORDESSES, R., HERVIER, C., COLTELLI, M., PRIVITERA, E. \& KORNPROBST, J. 2004. Doppler radar sounding of volcanic eruption dynamics at Mount Etna. Bulletin of Volcanology, 66, 443-456.

DUKLER, A. \& FABRE, J. 1994. GAS-LIQUID SLUG FLOW. Multiphase Science and Technology, 8.

DUMITRESCU, D. T. 1943. Strömung an einer Luftblase im senkrechten Rohr. ZAMM-Journal of Applied Mathematics and Mechanics/Zeitschrift für Angewandte Mathematik und Mechanik, 23, 139-149.

FURUKAWA, T. \& FUKANO, T. 2001. Effects of liquid viscosity on flow patterns in vertical upward gas-liquid two-phase flow. International Journal of Multiphase Flow, 27, 1109-1126.

GARCÉS, M. A. \& MCNUTT, S. R. 1997. Theory of the airborne sound field generated in a resonant magma conduit. Journal of Volcanology and Geothermal Research, 78, 155-178.

GOVAN, A., HEWITT, G., RICHTER, H. \& SCOTT, A. 1991. Flooding and churn flow in vertical pipes. International journal of Multiphase Flow, 17, 27-44.

GUET, S., OOMS, G., OLIEMANS, R. \& MUDDE, R. 2004. Bubble size effect on low liquid input driftflux parameters. Chemical Engineering Science, 59, 3315-3329.

HEWITT, G., MARTIN, C. \& WILKES, N. 1985. Experimental and modelling studies of annular flow in the region between flow reversal and the pressure drop minimum. Physico-Chemical Hydrodynamics, 6, 43-50.

HEWITT, G. F. \& HALL-TAYLOR, N. 1970. Annular two-phase flow, Pergamon.

HILLS, J. 1976. The operation of a bubble column at high throughputs: I. Gas holdup measurements. The Chemical Engineering Journal, 12, 89-99.

HOLT, A., AZZOPARDI, B. \& BIDDULPH, M. 1999. Calculation of two-phase pressure drop for vertical upflow in narrow passages by means of a flow pattern specific model. Chemical Engineering Research and Design, 77, 7-15.

JAYANTI, S. \& HEWITT, G. 1992. Prediction of the slug-to-churn flow transition in vertical two-phase flow. International Journal of Multiphase Flow, 18, 847-860. 
JAYANTI, S., HEWITT, G., LOW, D. \& HERVIEU, E. 1993. Observation of flooding in the Taylor bubble of co-current upwards slug flow. International Journal of Multiphase Flow, 19, 531-534.

KAYA, A. S., CHEN, X. T., SARICA, C. \& BRILL, J. P. 2000. Investigation of transition from annular to intermittent flow in pipes. Journal of Energy Resources Technology, 122, 22-28.

NICKLIN, D. 1962. Two-phase bubble flow. Chemical Engineering Science, 17, 693-702.

MARASHDEH, Q., 2009. Validation of Electrical Capacitance Volume Tomography with Applications to Multi-Phase Flow System [Masters of Science]. The Ohio State University, Columbus, OH.

OWEN, D. G. 1986. An experimental and theoretical analysis of equilibrium annular flows. University of Birmingham.

PAPANASTASIOU, T., GEORGIOU, G. \& ALEXANDROU, A. N. 1999. Viscous fluid flow, CRC Press. PHILIP, J., PROCTOR, J. M., NIRANJAN, K. \& DAVIDSON, J. F. 1990. Gas Hold-up and Liquid Circulation in Internal Loop Reactors Containing Highly Viscous Newtonian and Non-Newtonian Liquids. Chemical Engineering Science, 45, 651-664.

PRADEEP, C., YAN, R., VESTǿL, S., MELAAEN, M.C. and MYLVAGANAM, S., 2014. Electrical capacitance tomography (ECT) and gamma radiation meter for comparison with and validation and tuning of computational fluid dynamics (CFD) modeling of multiphase flow. Measurement Science and Technology, 25(7), p.075404.

RICHARDS, A. F. 1963. Volcanic sounds: Investigation and analysis. Journal of Geophysical Research, $68,919-928$.

SAWAI, T. \& KAJI, M. 2001. Flow structure and pressure gradient in churn flow. Experimental Heat Transfer, Fluid Mechanics and Thermodynamics, 2, 1791-1796.

SEKOGUCHI, K. \& MORI, K. 1997. New development of experimental study on interfacial structure in gas-liquid two-phase flow. Experimental Heat Transfer, Fluid Mechanics and Thermodynamics, 2, 1177-1188.

SHU, W. 1984. A viscosity correlation for mixtures of heavy oil, bitumen, and petroleum fractions. Society of Petroleum Engineers Journal, 24, 277-282.

SNABRE, P. \& MAGNIFOTCHAM, F. 1998. I. Formation and rise of a bubble stream in a viscous liquid. The European Physical Journal B-Condensed Matter and Complex Systems, 4, 369-377.

TAITEL, Y., BORNEA, D. \& DUKLER, A. 1980. Modelling flow pattern transitions for steady upward gas-liquid flow in vertical tubes. AIChE Journal, 26, 345-354.

VIANA, F., PARDO, R., YANEZ, R., TRALLERO, J. L. \& JOSEPH, D. D. 2003. Universal correlation for the rise velocity of long gas bubbles in round pipes. Journal of Fluid Mechanics, 494, 379398.

WALLIS, G. 1962. The onset of droplet entrainment in annular gas-liquid flow. General Electric Co. General Engineering Lab., Schenectady, NY.

WOULFF, G. \& MCGETCHIN, T. R. 1958. Acoustic noise from volcanoes: Theory and experiment. Geophysical Journal International, 1, 601-616.

ZUBER, N. \& FINDLAY, J. 1965. Average volumetric concentration in two-phase flow systems. Journal of heat Transfer, 87, 453-468. 